[Aus der dermatologischen Unitersitätsklinik zu Breslau.]

\title{
Ueber den Desinfectionswerth des Aethylendiaminsilberphosphats und Aethylendiamin- kresols, nebst Bemerkungen über die Anwendung der Centrifuge bei Desinfectionsversuchen.
}

Von

Jean Schäffer,

Assistenzarzt der Klinik.

Experimentelle Forschung sowohl als klinische Erfahrung haben in den letzten Jahren die antiseptische Wirkung der Silberlösungen immer mehr schätzen gelehrt. Zahlreiche Desinfectionsversuche zeigten die sehr bedeutende keimtödtende Eigenschaft der Argentumverbindungen, die unter gewissen Bedingungen selbst dem Sublimat überlegen waren, und die erfolgreiche Anwendung, welche das Argentum nitricum seit langer Zeit in der ärztlichen Praxis findet, bestätigt durchaus die günstigen Resultate des Experiments.

In seiner Arbeit über den antiseptischen Werth der Silberlösungen (1) sagt Behring, dass in Blut und blutähnlichen Flüssigkeiten das Silber unter allen bisher geprüften antiseptischen Mitteln das leistungsfähigste sei und fünfmal mehr leiste als Quecksilberchlorid. In einer anderen Schrift desselben Forschers: Ueber Desinfection, Desinfectionsmittel und Desinfectionsmethoden (2) heisst es: „Man darf wohl behaupten, dass die Desinfectionskraft des Silbers noch viel zu wenig gewürdigt wird" und wenige Zeilen später: „Erst in der Gonorrhoe-Therapie der neueren Zeit wird durch Anwendung stark verdünnter Höllensteinlösungen zielbewusst die antiseptische Wirkung ausgenutzt".

In der That haben bei der Behandlung dieser Krankheit die schwachen Silberlösungen an Wirksamkeit die übrigen Nittel übertroffen und grossentheils verdrängt; dagegen hat sich bei der therapeutischen Anwendung des vornehmlich gebrauchten Silbernitrats ein Uebelstand von nicht zu 
unterschätzender Bedeutung bemerkbar gemacht. - Wir wissen durch neuere Untersuchungen bewährter Forscher, dass die Gonokokken nach verhältnissmässig kurzer Zeit in die Tiefe des Epithels dringen. Es ist demnach unbedingtes Erforderniss einer rationellen Therapie, dass das angewandte Mittel nicht nur oberflächlich wirkt, sondern die Krankheitserreger auch in den tieferen Gewebsschichten erreicht und abtödtet. Diese Bedingung kann das Argentum nitricum nur unvollkommen erfüllen. Seine Wirkung ist eine verhältnissmässig oberflächliche. Es bildet nämlich mit kochsalz- und eiweisshaltigen Substanzen unlösliche Verbindungen, welche an der Oberfläche liegen bleiben und auch der nachfolgenden Flüssigkeit den Weg in die Tiefe versperren. ${ }^{3}$ Es lag somit das Bedürfniss vor, eine Silberlösung herzustellen, welche einerseits die energische bakterientödtende Eigenschaft des Argentum beibehielt, andererseits aber mit Kochsalz und Eiweisskörpern in geringerem Maasse unlösliche Verbindungen einging.

Von diesem Gesichtspunkte ausgehend stellte die chemische Fabrik auf Actien (rormals E. Schering) Versuche an, welche zur Herstellung einer Aethyle ndiaminsilberphosphatlösung führten. Untersuchungen, welche in der erwähnten Fabrik angestellt wurden, ergaben, dass das Aethylendiamin nur geringe Aetzwirkung besitzt, und dass beim Zusatz der alkalischen Silberlösung zu einer eiweiss- und kochsalzhaltigen Flüssigkeit keine Fällung, sondern nur eine Trübung entsteht. Das phosphorsaure und nicht das salpetersaure Silbersalz wurde aus dem Grunde gewählt, weil in letzterem Falle unerwünschte Nebenwirkungen des bei der Darstellung aus Silbernitrat sich bildenden Aethylendiaminnitrats gefürchtet wurden.

Das Aethylendiaminsilberphosphat ist eine farblose, klare Flüssigkeit, welche noch einmal so viel Aethylendiamin als Silberphosphat enthält; die alkalische Reaction der Lösung ist abbängig ron dem Gehalt an Aethylendiamin, von welchem $100^{\mathrm{ccm}}$ einer 10 procentigen Lösung $333^{\mathrm{ccm}}$ Normalnatronlauge entsprechen. Das Präparat muss ebenso wie die übrigen Silbersalze im Dunklen aufbewahrt werden, da es sonst leicht Zersetzungen eingeht.

Fs handelte sich nun darum, die Wirksamkeit des Aethylendiaminsilberphosphats experimentell zu prüfen, insbesondere seine Tiefenwirkung und den Desinfectionswerth festzustellen; ${ }^{2}$ gleichzeitig wurden bezüglich

\footnotetext{
${ }^{1}$ Es gilt dies besonders von den starken Höllensteinlösungen, während die ganz schwachen nur sehr geringe Niederschläge in kochsalz- und eiweisshaltiger Flüssigkeit hervorrufen.

${ }^{2}$ Ich erwähne, dass Behring in seiner unter (1) citirten Arbeit eine Pentamethylendiaminsilberoxydlösung antersucht und deren hohen antiseptischen Werth
} 
der praktischen Verwerthbarkeit des Mittels zahlreiche Erfahrungen gesammelt, über welche demnächst an anderer Stelle berichtet werden soll. Ehe ich an die Prüfung des neuen Präparates gehe, will ich die hier in Betracht kommenden Eigenschaften der organischen Verbindung schildern, welche bisher in pharmakologischer Hinsicht noch nicht untersucht ist.

Das Aethylendiamin hat die chemische Formel:

$$
\mathrm{C}_{2} \mathrm{H}_{4}<\underset{\mathrm{NH}_{2}}{\mathrm{NH}_{2}} \text {. }
$$

Es ist eine vollständig klare und farblose Flüssigkeit, deren specifisches Gewicht 0.97 beträgt. In Wasser löst es sich leicht, die Reaction ist stark alkalisch, der Geruch ammoniakähnlich. Bei Einwirkung von salpetriger Säure treten leicht Umsetzungen ein.

In erster Reihe wurde die Fähigkeit des Aethylendiamins Chlorsilber zu lösen geprüft, welches, wie bereits erwähnt, bei der Einwirkung von Silbersalzen auf die stets kochsalzhaltigen Gewebsflüssigkeiten entsteht. $\mathrm{Zu} 1^{\mathrm{cem}}$ physiologischer Kochsalzlösung wird die gleiche Menge Arg. nitr. 1:2000 zugesetzt, wobei ein weisser Niederschlag von $\mathrm{AgCl}$ sich bildet; giesst man nun einige Tropfen einer 1 procentigen Aethylendiaminlösung hinzu, so wird der Inhalt des Reagensglases durchsichtiger und nach Zusatz von $1 / 2$ bis ${ }^{9} / 4$ coin vollständig klar. Es ist also das Chlorsilber durch das Aethylendiamin gelöst worden. Besonders hervorzuheben ist noch, dass das so gelöste $\mathrm{AgCl}$, selbst nach 12 stündiger Einwirkung des hellen Tageslichtes keine Trübung in Folge von chemischer Umsetzung zeigte, während ausgefälltes Chlorsilber ohne Aethylendiaminzusatz schon nach $1 / 2$ Stunde sich schwärzte.

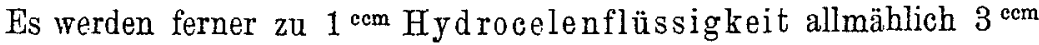
Arg. nitr.-Lösung 1:2000 zugefügt, wobei eine Trübung und schliesslich ein schwacher Niederschlag entsteht. Beim Zusatz von nur wenigen Tropfen einer 1 procentigen Aethylendiaminlösung hellte sich die Flüssigkeit schnell auf, etwa 18 bis 20 Tropfen genügten, um die Lösung klar und durchsichtig zu machen. Es hatten sich hierbei nicht nur Chlorsilber, sondern auch die beim Zusatz des Argentum nitricum zu der sehr eiweissreichen Flüssigkeit entstehenden Silberoxydeiweissverbindungen gelöst.

hervorgehoben hat; ich beabsichtigte anfänglich vergleichende Untersuchungen mit dem genannten Präparate anzustellen, konnte indessen nicht in den Besitz desselben gelangen. Es konnte um so eher auf eine vergleichende Prüfung verzichtet werden, als ich die Mittheilung erhielt, dass eine technische Darstellnng des Pentamethylen. diaminsilberoxyds unmöglich, und die praktische Verwendung des Mittels so gut wie ausgeschlossen sei. 
Vermischung eines Cubikcentimeters einè 1 procentigen Höllensteinlösung mit der gleichen Menge Hydrocelenflüssigkeit rerursachte einen erheblichen Niederschlag, der beim Zusatz von 1 procent. Aethylendiamin sehr bald geringer wurde; zur vollständigen Aufhellung waren jedoch fast $3^{\mathrm{ccm}}$ nothwendig.

Menschliches Blutserum gab mit der gleichen Menge einer $1 / 2 \%$ Silbernitratlösung eine deutliche Trübung, die durch wenige Tropfen 1 procent. Aethylendiamin sogleich zum Verschwinden gebracht wurde. Auch die sehr intensive Trübung, welche eine 1 procentige Arg. nitr.Lösung im Serum verursachte, wurde durch Aethylendiamin vollständig beseitigt.

Besonders interessant und praktisch wichtig ist die Thatsache, dass das Aethylendiamin die Fähigkeit besitzt, Eiterkörperchen aufzulösen.

Wurde $1^{\mathrm{ccm}}$ Eiter, welcher aus einem phlegmonösen discess des Unterarmes entleert worden war, mit $10^{\mathrm{cem}}$ einer 4 procentigen Aethylendiaminlösung vermischt, so entstand eine durchscheinende Masse von gleichmässig dickflüssiger Consistenz.

In $15^{\mathrm{ccm}}$ einer 2 procentigen Lösung wurden die Eiterkörperchen, welche in $1 \mathrm{cem}$ desselben Eiters enthalten waren, vollständig aufgelöst; mikroskopisch sah man nur vereinzelte detritusähnliche Körnchen. Beim Zusatz von $10^{\mathrm{ccm}}$ der $1 / 2$ procentigen Lösung zu $1 \mathrm{~cm}$ Eiter wurde die Flüssigkeit schwach trüb und zeigte auch bei längerem Stehen keinen Bodensatz.

Dem Blute gegenüber verhielt sich das Aethylendiamin folgendermassen. $1 \mathrm{cem}$ frischen menschlichen Blutes gab mit $10^{\mathrm{ccm}}$ der $1 / 2$ proc. Lösung eine vollständig durchsichtige Flüssigkeit, in welcher mikroskopisch rothe Blutkörperchen nicht zu erkennen waren. Schliesslich wurde noch folgender Versuch angestellt: Drei etwa bohnengrosse Blutgerinnsel werden in Reagensgläschen gebracht, zu dem einen $10 \mathrm{cem}$ destillirten Wassers, zum zweiten ebenso viel $1 / 2$ procent. Aethylendiamin und zum dritten die gleiche Menge der 20 procentigen Lösung zugesetzt. Das Gerinnsel im ersten Glas blieb unverändert, abgesehen daron, dass etwas Farbstoff ausgelaugt wurde, im zweiten Reagensglase stellte das Blutgerinnsel eine glasige, durchsichtige Masse dar, während es durch die starke Aethylendiaminlösung im dritten Gläschen bis auf ganz geringe Spuren gelöst wurde.

Wenn es auch nach den bisher mitgetheilten Versuchen wahrscheinlich war, dass das Aethylendiamin die Fähigkeit besitzen würde, in's organische Gewebe einzudringen und einem Silbersalze beigemischt diesem den Weg in die Tiefe zu bahnen, so war es doch wünschenswerth, dies 
auch direct beweisen zu können. Bevor ich dies versuche, will ich kurz einige Vorversuche erwähnen.

Reagensgläschen mit horizontal erstarrter Gelatine werden mit $1 / 2$ proc. Arg. nitr.-, bezw. ${ }^{1} / 2$ procentiger Aethylendiaminsilberlösung ${ }^{1}$ übergossen und im Dunklen aufbewahrt. Nach 10 Stunden wurden die Gläschen dem hellen Tageslicht ausgesetzt, wobei die klaren Silberlösungen schnell dunkel wurden. Jetzt war deutlich sichtbar, dass das Silberphosphat etwa 9 bis $10 \mathrm{~mm}$ in die Gelatine eingedrungen war, indem die oberste Gelatinesehicht den bräunlichen Farbenton, welcher dem durch die Lichtwirkung zersetzten Silbersalz entspricht, in der angegebenen Breite zeigte. .Die bräunliche Zone wird nach unten zu etwas blasser, um dann noch etwa $2^{\text {rim }}$ als dunkelgelb gefärbte Schicht in die hellgelbe Farbe dex Gelatine überzugehen. Die mit $1 / 2$ proc. Arg. nitr.-Lösung übergossene Gelatine zeigte an der Obertäche gleichfalls eine dunkelbraun gefärbte Zone, die jedoch nur $1 \mathrm{~mm}$ breit und sehr seharf begrenzt war.

Mehrere Versuche derselben Art, welche ich nicht einzeln schildern will, lehrten, dass das Eindringen des Aethylendiaminsilberphosphats abgesehen von der Einwirkungszeit ron dem Gehalt an Aethylendiamin abhängig war, und dass selbst in ganz schwacher Concentration (z. B. 1:4000) ein deutlicher Unterschied zu Gunsten der alkalischen Silberlösung bemerkbar war.

Um nun die Tiefenwirkung der verschiedenen Argentumverbindungen direct an organischem Gewebe nachweisen und demonstriren zu können, wurde folgendermassen verfahren.

Gleichgrosse, würfelförmige Stücke der Leber eines eben getödteten Kaninchens (mit einer Peritoneal- und 5 Parenchymflächen) werden in eine Lösung von Arg. nitr. 1:2000 und von Aethylendiaminsilberphosphat mit genau gleichem Silbergehalt gebracht und 10 Stunden lang im Dunkeln gehalten. Nach dieser Zeit werden die Leberstücke in eine verdünnte Lösung von Schwefelammonium für einige Secunden gebracht, wobei die Würfel durch Bildung von Schwefelsilber sich schwarz färben. Hierauf werden dieselben in Wasser abgespült und mit Hülfe des Gefriermikrotoms geschnitten. Die Schnitte werden sogleich mit verdünntem Schwefelammonium behandelt, in Wasser reichlich ausgewasehen und zur mikroskopischen Betrachtung in gewöhnlicher Weise aufgelegt. Die schwach gelblich gefärbten Schnitte haben einẹn deutlichen, dunkelbraunen,

1 Es sei von vornherein bemerkt, dass aus praktischen Gründen als eine 10 procentige Aethylendiaminsilberphosphatlösung diejenige bezeichnet warde, welche ebenso viel Silber enthielt als eine 10 procentige Arg. nitr.-Lösnng. Bei den folgenden Versuchen gleichen sich also Lösungen von derselben Concentration mit Bezug auf ihren Silbergehalt.

Zeitschr. f. Hygiene. XVI. 
fast sehwarzen Saum; bei den mit Arg. nitr. behandelten Präparaten stellte derselbe eine kaum $1 \mathrm{~mm}$ breite, scharf begrenzte Linie dar, bei den mit Aethylendiaminsilberphosphat behandelten Schnitten war er beträchtlich breiter (fast $3 \mathrm{~mm}$ breit), und die Abgrenzung nach dem Parenchym zu weniger scharf, mit zahlreichen, feinen Ausläufern versehen. Bei schwacher Vergrösserung war die grössere Breitenausdehnung des Streifens der letzterwähnten Schnitte klar sichtbar, wie auch mit Deutlichkeit zu erkennen war, dass die durch Schwefelsilber bezeichnete Zone entsprechend den Leberzellbalken sich streifenförmig in die Tiefe fortsetzte.

Es ist nun klar, dass überall dort, wohin das Argentumsalz gedrungen war, sich Schwefelsilber bilden musste, und dass somit der braune Niederschlag ein sicheres Kriterium für die Tiefenwirkung der beiden Silberlösungen war. Bei weitem deutlicher und noch überzeugender waren die Resultate mit einer stärkeren ( $1 / 2$ proc.) Arg. nitr.- und Aethylendiaminsilber-Lösung. Es wurden wiederum 4 würfelförmige Leberstückchen (einem soeben getödteten Kaninchen entnommen) möglichst gleich gross hergestellt; sie hatten 1 Peritoneal- und 5 Parenchym-Flächen. Je zwei werden in eine $1 / 2$ proc. Arg. nitr. bezw. eine $1 / 2$ proc. Silberphosphatlösung gebracht und 6 Stunden in derselben gelassen. Hierauf werden die Stücke genau in der oben beschriebenen Weise behandelt und geschnitten. Es zeigte sich hierbei, dass die Parenchymflächen bröcklig und weich geworden waren, so dass sich beim Schneiden Gewebstheilchen loslösten; diese Flächen waren also kein geeignetes Object für die Beurtheilung des Eindringens der Silberlösungen in's Gewebe. Dagegen bemerkte man an der vollständig erbaltenen Peritonealfäche der mit Schwefelammonium behandelten Schnitte einen sehr bedeutenden Unterschied in der Breitenausdehnung der mit Schwefelsilber durchsetzten Randzone. Letztere stellt bei den Schnitten, die vorher dem Arg. nitr. ausgesetzt waren, einen ziemlich scharf begrenzten, schmalen Streifen dar, während die dunkelbraune Zone der Silberphosphatpräparate mehr als 5 mal so breit ist und ganz allmählich in das helle Lebergewebe übergeht. Die mikroskopische Betrachtung zeigte mit noch grösserer Deutlichkeit die bereits beim ersten Versuch angedeuteten Thatsachen; hier der schmale Streif, dort die breite Randzone, welche lange Fortsätze, entsprechend den Leberzellbalken, in die Tiefe schickt, gleichsam als ob bei längerer Einwirkung die Lösung noch weiter in's Gewebe zu dringen vermöchte im Gegensatz zum Argentum nitricum-Schnitt, der den Eindruck eines definitiven Abschlusses der Tiefenwirkung hervorruft. Die geschilderten Verhältnisse sind veranschaulicht durch zwei Mikrophotogramme, welche die Peritonealfläche des mit $1 / 2$ proc. Arg. nitr. (Fig. 1) und des mit $1 / 2$ procent. Aethylendiaminsilberphosphat (Fig. 2) behandelten Leberstückchens darstellen. Die Vergrösserung ist 
ǓBER D. DESINFECTIONSWERTH D. AETHYLENDIAMINSILBERPHOSPEATS. 195

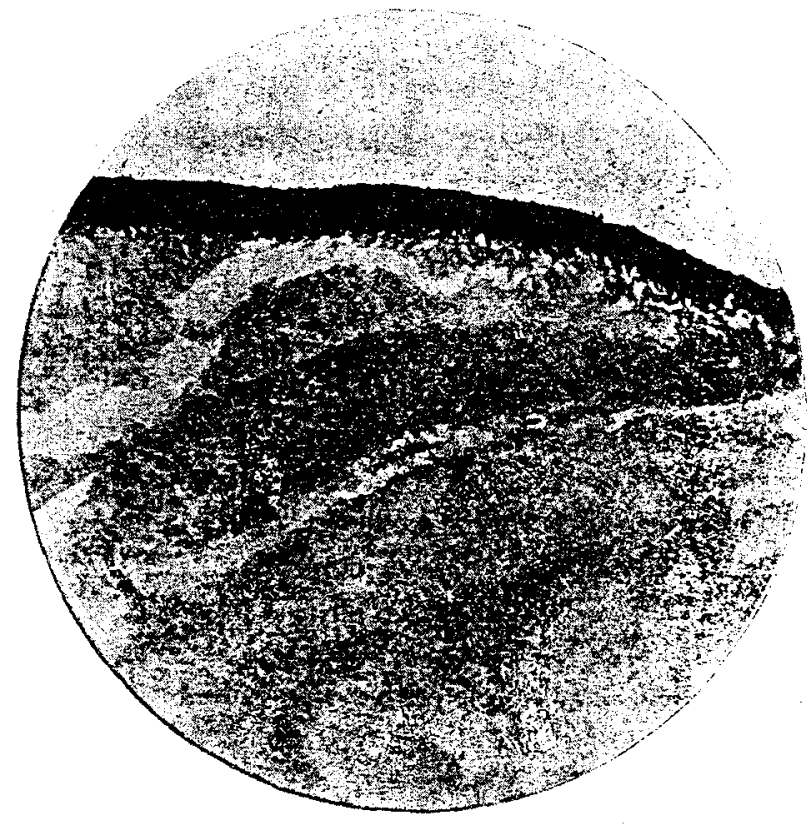

Fig. 1.

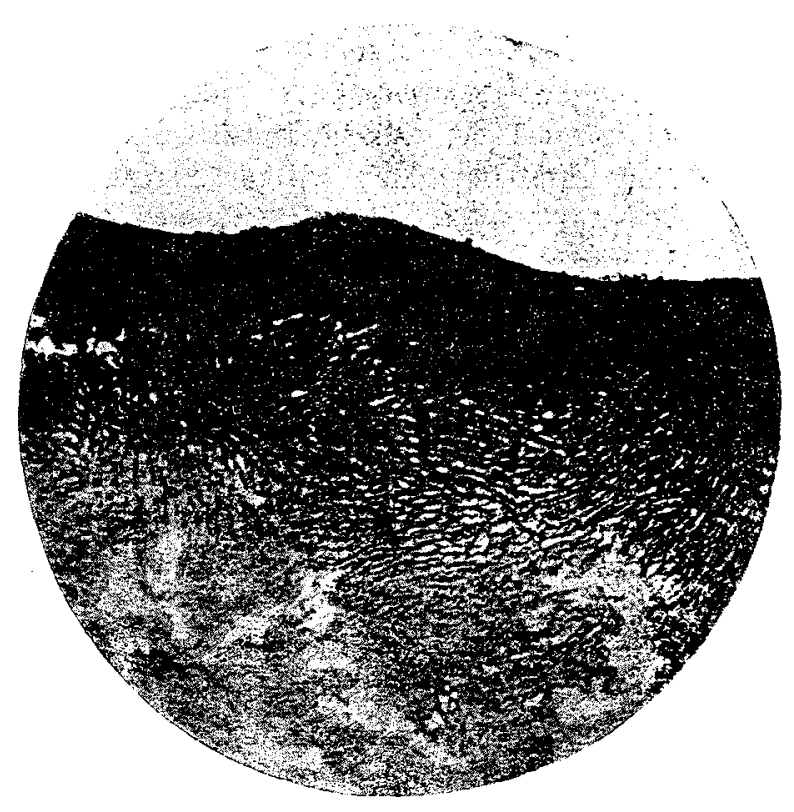

Fig. 2. 
für beide Figuren die gleiche und beträgt 30. Auf Fig. 1 sieht man eine schräg verlaufende Falte des Lebergewebes.

Durch die mitgetheilten Versuche ist also unzweifelhaft nachgewiesen, dass eine Aethylendiaminsilberphosphatlösung viel tiefer in's organische Gewebe eindringt als eine Arg. nitr.Lösung von ebendemselben Sibergehalt, in der gleichen Zeit, unter genau denselben Bedingungen. Die erhebliche Tiefenwirkung, welche auf diese Weise für das Silberphosphat gegenüber dem todten Gewebe zu constatiren war, liess sich auch mit Bezug auf lebendes Gewebe darthun.

Hierzu bot sich eine günstige Gelegenheit bei einem Patienten mit einem gonorrhoisch erkrankten, paraurethralen Gang, welcher aus therapeutischen Gründen excidirt werden sollte. 15 Minuten vor der Operation wurde mit einer Pravaz'schen Spritze, deren Canüle conisch abgestumpft war; eine 8 procentige Aethylendiaminsilberlösung injicirt, und der Anfang des Ganges durch eine Seidennaht abgebunden, so dass die eingespritzte Flüssigkeit nicht wieder abfliessen konnte. Nachdem nun die Silberlösung 15 Winuten eingewirkt hatte, wurde der Gang mit einem Scheerenschlage excidirt, der Seidenfaden gelöst und in das Lumen Schwefelammonium injicirt, um nach Möglichkeit die Wirkung der noch zurückbleibenden Argentumlösung auszuschalten. Das so gewonnene Präparat wird in Celloidin eingebettet, in Querschnitte zerlegt und genau wie oben mit Schwefelammonium behandelt. Ich begnüge mich damit anzuführen, dass der Niederschlag des dunklen Schwefelsilbers im Gewebe auch hier eine deutliche Tiefenwirkung trotz der kurzen Einwirkungsdauer zeigte; eine genauere Beschreibung des Präparates soll an anderer Stelle gegeben werden.

In zweiter Reihe war es nothwendig die Giftigkeit der nenen Silberlösung durch das 'Thierexperiment zu bestimmen, ehe man das Präparat zur Einführung in die Praxis empfehlen konnte. Zahlreiche Versuche an Kaninchen und weissen Mäusen haben nun gezeigt, dass die Giftwirkung der alkalischen Silberverbindung im Wesentlichen abhängig ist von dem Gehalte an Argentum; das letztere ist mit Bezug auf seine schädlichen Eigenschaften bereits genügend erforscht, insbesondere hat Behring gefunden, dass die Giftigkeit des Silbers im Vergleich zu seiner hohen antiseptischen Kraft ejne verhältnissmässig geringe ist. Experimente an weissen Mäusen haben nun allerdings gelehrt, dass die Thiere durch Aethylendiaminsilberphosphat etwas früher starben, als durch dieselbe Menge einer gleichprocentigen Arg. nitr.-Lösung; indessen ist dies wohl weniger auf den Gehalt an Aethylendiamin, als vielmehr auf die schnellere und grössere Resorption des leichter in's Gewebe eindringenden Silbers 
zu beziehen. Die locale entzündliche Reaction, welche die subcutane Injection des Silberphosphats hervorrief, war eine äusserst geringe. $2^{\mathrm{cem}}$ einer 1 procentigen Lösung verursachten bei einem Kaninchen kaum entzündliche Erscheinungen, ebenso wenig die subcutane Einverleibung von $1 /{ }^{\mathrm{c}} \mathrm{cm}$ derselben Lösung bei einer weissen Maus; in beiden Fällen war nach 24 Stunden die Injectionsstelle nicht mehr fühlbar.

Von besonderer Wichtigkeit schien mir die Prüfung der Giftigkeit des Aethylendiamins zu sein, da hierüber bisher noch keine Versuche gemacht worden sind. Kaninchen vertrugen $0.4 \mathrm{grm}$ Aethylendiamin ohne merkliche Beeinträchtigung der Gesundheit, vorausgesetzt, dass die Concentration der injicirten Lösung keine zu starke war; eine 20 procentige Lösung bewirkte bereits erhebliche Aetzung des Gewebes, 2 eem einer 36 procentigen Lösung verursachten bei einem Kaninchen ein flächenhaftes, sehr derbes Infiltrat, das sich erst nach einigen Wochen resorbirte. An der betreffenden Stelle wurde auch Haarausfall beobachtet. Weisse Mäuse vertrugen bis $0.03 \mathrm{grm}$ Aethylendiamin ( 1 cem einer 3 procentigen Lösung); bei höheren Dosen trat der Tod ein, sei es, dass die Aetzwirkung. bei der höheren Concentration oder die toxische Wirkung auf den Gesammtorganismus den Tod der Thiere veranlasste. Jedenfalls ging aus den Thierexperimenten hervor, dass die Giftwirkung des Aethylendiamins zu gering ist, als dass sie bei der praktischen Verwendung der Aethylendiaminpräparate störend sein konnte.

Ehe ich an die Prüfung der Desinfectionskraft des neuen Mittels gehe, will ich noch kurz eine Untersuchung über den Einfluss des Aethylendiaminpräparates auf das Verhalten der Gefässe mittheilen. Ich wurde hierzu veraulasst durch die Thatsache, dass das Aethylendiaminsilberphosphat im Gegensatz zur styptischen Wirkung des Argentum nitricum auf einer frischen Wundfläche selbst bei Verwendung einer 8 procentigen Lösung die Blutung sichtlich vermehrte. Es lag nun nahe, anzunehmen, dass dies auf die viel geringere Eiweisscoagulation und auf die Auflösung der Blutgerinnsel zurückzuführen war, welche das Aethylendiamin den obigen Auseinandersetzungen zu Folge zu Stande bringen konnte. Nichtsdestoweniger war die Erscheinung so auffällig, dass es der Mühe werth schien, zu prüfen, ob dieselbe rielleicht ausserdem noch durch ein verschiedenes Verhalten der neuen Silberlösung gegenüber den Gefässen bedingt war, zumal da es auch für die sonstige Verwendung. des Mittels von Wichtigkeit war zu constatiren, ob es in geringerer Concentration ebenso wie Arg. nitr. als Adstringens wirkte. Der diesbezügliche Versuch wurde folgendermassen angestellt. Die Zunge eines curaresirten Frosches wird ausgespannt, und unter dem Mikroskop eine Stelle mit Gefässen von verschiedener Grösse eingestellt. Hierauf werden einige 
Tropfen einer 0.1 procentigen Arg. nitr.-Lösung aufgeträufelt, wobei sehr bald eine deutliche Verengerung sämmtlicher Gefässlumina wahrnehmbar wird, welche bei wiederholter Beträufelung nicht zunimmt. Nach etwa 5 Minuten werden 2 Tropfen einer $1 / 2$ procentigen Arg. nitr.-Lösung aufgetropft; es entsteht eine unwesentliche Erweiterung der Gefässe, was sich indess nur schwer beobachten lässt, da eine erhebliche Trübung des Bildes durch Eiweissgerinnung eingetreten ist, und die Gefässcontouren nicht mehr dentlich zu erkennen sind. Bei Benetzung einer anderen noch intacten Stelle der Zunge mit einer 10 procentigen Höllensteinlösung schien, soweit die Trübung dies erkennen liess, eine Gefässerweiterung einzutreten. Ein gleicher Versuch wurde mit entsprechenden Aethylendiaminsilberphosphatlösungen angestellt, wobei sich genau dasselbe Ergebniss bezüglich des Verhaltens der Gefässe herausstellte. Es waren hierbei die Vorgänge viel deutlicher zu beobachten, da die Trübung beim Zusatz der stärkeren Lösungen viel geringer war. Auch makroskopisch war beim Betropfen der Froschzunge mit 10 procent. Argentum nitricum die Bildung eines weisslichen Belages wahrzunehmen, während bei Benetzung mit der 10 procentigen Silberphosphatlösung sich nur ein schleimiger, leicht getrübter Veberzug bildete. Der Versuch lehrte also, dass das neue Silbersalz in schwacher Concentration ebenso gefässverengernd wirkt wie die Arg. nitr.-Lösungen, und dass für die oben erwähnte Eigenschaft auf frischen Wundflächen die Blutung $z$ u steigern nicht die Beeinflussung der Gefässe, sondern die geringere Bildung unlöslicher Eiweissverbindungen massgebend ist.

Ich komme nun zur experimentellen Prüfung der antibakteriellen Eigenschaften des Aethylendiaminsilberphosphats.

Von mancher Seite sind gegen den Werth von Desinfectionsversuchen Einwände erboben worden, welche nicht ohne Weiteres ron der Hand gewiesen werden können. Offenbar sind die Bedenken, welche man gegen derartige bakteriologische Untersuchungen vorbringen kann, zweierlei Art. Erstens kann man anführen, dass viele der angewandten Methoden zahlreiche Fehlerquellen enthalten, so dass die Resultate unzutreffend und unzuverlässig sind. Zweitens wird eingewandt, dass selbst bei fehlerfreier Yethode die Verhältnisse der Reagensglasversuche so verschieden von denjenigen in der Desinfectionspraxis sind, dass eine Uebertragung der im Laboratorium gefundenen Werthe auf die Verhältnisse bei der praktischen Verwendung nicht statthaft ist. Es ist nicht zu leugnen, dass der zweite kinwand eine gewisse Berechtigung hat. Wir können zwar die Versuchsanordnung bei der Desinfectionsprüfung so treffen, dass wir die Be- 
dingungen, unter denen das Mittel seine Anwendung finden soll, berücksichtigen und bis zu einem gewissen Grade die Verhältnisse nachahmen; vollständig werden wir dies jedoch nicht erreichen können, besonders daun nicht, wenn es sich um ein Desinficiens handelt, das seine Wirksamkeit am lebenden Organismus entfalten soll. Hier muss eben die praktische Erfahrung die Ergebnisse der Reagensglasversuche ergänzen, und wir müssen uns damit begnügen, durch das Experiment orientirende Werthe zu finden, was um so leichter und vollkommener zu erreichen ist, wenn wir Vergleichswerthe mit bekannten und praktisch bereits erprobten Mitteln suchen.

Hinsichtlich des ersten Einwandes ist zuzugeben, dass derselbe mit Bezug auf einen grossen Theil der Untersuchungsmethoden durchaus berechtigt ist; andererseits sind aber auf dem Gebiete der Desinfectionstechnik gerade in der neueren Zeit bedeutende Fortschritte gemacht worden, so dass die Resultate sicherer und zuverlässiger sind. Man ist in den letzten Jahren auf Fehlerquellen aufmerksam geworden, welche vorher der Beachtung entgangen waren. Die Anforderungen, welche heute an die richtige Prüfung eines Desinfectionsmittels gestellt werden, sind strengere als früher, und die meisten der ehemals geübten Methoden halten der Kritik nicht mehr Stand. Es ist durchaus nothwendig, bei der Prüfung eines Antisepticums die Versuchsfehler, auf welche in der neueren Litteratur hingewiesen worden ist, nach Möglichkeit zu vermeiden; nur unter dieser Bedingung wird der oben erwähnte Einwand seine Gültigkeit verlieren. Es fragt sich nun, welche Versuchsanordnung am geeignetsten ist, diese Bedingung zu erfüllen; in Betracht kommen hierbei wesentlich zwei Methoden, einerseits die Methode der Seidenfäden, andererseits die der Bakterienaufschwemmungen.

Die erste Methode, welche wohl am allermeisten angewendet worden ist, hat unleugbar sehr grosse Vorzüge, besonders wenn es sich um die Prüfung eines Antisepticums handelt, das unter ähnlichen Verhältnissen seine praktische Verwendung finden soll, z. B. zur Desinfection von Kleidern und Stoffen. Andererseits lassen sich aber gegen diese Versuchsanordnung schwerwiegende Bedenken geltend machen, wie dies auch von mancher Seite geschehen ist.

Eine der wichtigsten Bedingungen, die bei derartigen Versuchen erfüllt sein müssen, ist offenbar diejenige, dass das Desinficiens zu den Mikroorganismen, auf welche es wirken soll, möglichst leicht und schnell gelangen kann. Hier ist dies jedoch nicht der Fall; vielmehr ist es sehr leicht möglich, dass einzelne Bakterien in Folge ihrer geschützten Lage später, bei kurzer Versuchsdauer vielleicht gar nicht von der zu prüfenden Flüssigkeit erreicht werden. 
Auf den zweiten Punkt, der gegen die Anwendung der Seidenfädenmethode angeführt werden kann, hat $\mathrm{Koch}$ selbst in seiner bekannten Arbeit über Desinfection (3) hingewiesen. Es ist unvermeidlich, dass bei der Uebertragung des Fadens aus der Desinfectionsflüssigkeit Spuren der letzteren auf den neuen Nährboden gebracht werden, wodurch dieser für das Wachsthum der Bakterien ungeeignet werden kann. Um diesen Versuchsfehler zu verringern, schlug $\mathrm{Koch}$ vor, nur wenig zu übertragen, reichlichen Nährboden zu nehmen und das dem Faden anhaftende Desinficiens durch Auswaschen $z u$ entfernen. Trotz aller dieser Vorsichtsmassregeln lässt sich der Fehler nicht vollständig ausschalten, zumal wenn es sich um ein sehr energisches Antisepticum handelt, das selbst in ungemein schwacher Verdünnung entwickelungshemmende Wirkung entfaltet.

Besser geeignet zur Vermeidung der angeführten Mängel erscheint die Deckgläschenmethode, wie sie Geppert (4) und in ausgedehnterem Mlaasse Spirig (5) zu ihren Versuchen benutzten. Gereinigte, sterile Deckgläschen werden mit Bakterienaufschwemmungen befeuchtet, und alsdann die Austrocknung vorgenommen. Man kann nun diese angetrockneten Mikroorganismen eine beliebige Zeit dem Desinficiens aussetzen und vor dem Uebertragen der Deckgläschen die anhaftende Flüssigkeit durch Auswaschen mit Alkohol oder Wasser entfernen. In ähnlicher Weise verfuhr Buttersack in einer Arbeit über die Kresole (6), in der er die Mikroorganismen an Glasfäden antrocknete und mit diesen die Desinfectionsexperimente vornahm. Mit Hülfe dieser Methoden ist die Nitübertragung von Desinficiens auf den frischen Nährboden auf ein Minimum zu reducireri; indessen lässt. sich der Einwand erheben, dass das Eintrocknen der Mikroorganismen wenigstens bei manchen Arten derselben keineswegs gleichgültig ist. Ferner ist - freilich mehr rom theoretischen als vom praktischen Standpunkt aus - zu erwähnen, dass die $z \mathbf{u}$ prüfende Flüssigkeit zwar sehr leicht zu den einzelnen Mikroorganismen gelangen kann, dass aber immerhin eine Fläche derselben, nämlich diejenige, mit welcher die Bakterien dem Glas anhaften, geschützt vor dem Desinficiens bleibt.

Aus diesen Gründen habe ich auch die letzterwähnten Methoden nicht angewandt, sondern mit Bakterienaufschwemmungen gearbeitet, wie sie Geppert in seiner Arbeit über desinficirende Mittel und Methoden (4) angegeben hat. Dieses Verfahren scheint mir das geeignetste zur Vermeidung der Fehlerquellen zu sein und am meisten den Anforderungen zu entsprechen, welche heute an die einwandfreie Prüfung eines Antisepticums gestellt werden müssen. "Auf den filtrirten Suspensionen", sagt Geppert in der citirten Abhandlung, „basirt die einzige Versuchs- 
Über D. DesinfECTIONSWERTH D. AETHYLENDTAMINSICBERPHOSPHATS. 201

anordnung, welche eine wirklich innige Berührung jeder einzelnen Spore mit dem Desinfectionsmittel garantirt, und welche ferner gestattet, im gegebenen Moment das Desinfectionsmittel beliebig zu verdünnen oder chemisch unschädlich zu machen."

Die Bakterienaufschwemmungen habe ich auf folgende Weise hergestellt. Reinculturen der betreffenden Mikroorganismen, die reichlich auf schräg erstarrtem Agar gewachsen waren, werden rermittelst der Platinöse in steriles Wasser gebracht, und zwar werden im Allgemeinen zu je 3 cem Aufschwemmung die Culturen eines Röhrchens verwendet. Die so gewonnene, fast stets noch grössere Flocken enthaltende Suspension wird nach Geppert's Vorchrift mit Hülfe von Glaswolle filtrirt, bis grössere Partikelchen mit blossem Auge nicht mehr sichtbar sind. Die gleichmässig getrübte Flüssigkeit wird nun unter Errärmung im Wasserbade von $37.5^{\circ} \mathrm{C}$. so lange energisch gesehüttelt, bis die mikroskopische Untersuchung einer mit der Platinöse entnommenen Probe lehrte, dass die Mikroorganismen nicht mehr zu grösseren Haufen vereinigt, sondern so weit isolirt sind, dass sie der Einwirkung des Desinfectionsmittels leicht zugänglich sind. Erst nachdem dies mit Sicherheit festgestellt war, wurde die Aufschwemmung in abgemessener Menge (gemöhnlich $3^{\mathrm{ccm}}$ ) in sterile Reagensgläschen gebracht. Dies geschah mit einer graduirten, $10^{\mathrm{cm}}$ fassenden Glasröhre, die unten leicht zugespitzt war und am oberen Ende durch einen Schlauch mit einer Spritze in Verbindung stand. Letztere besass eine Einrichtung, welche es gestattete, die Flüssigkeit aus der Röhre in gleich grossen Tropfen zu entleeren. Mit Hülfe dieser Vorrichtung war es leicht möglich bestimmte Flüssigkeitsmengen - einem jeden Theilstrich entsprach $1 / 10^{\mathrm{ccm}}$ - genau abzutheilen. Vor jeder Benutzung wurde die Röhre im Wasserdampf sterilisirt. Gewöhnlich wurden 3 oder 4 Reagensgläser mit je $3^{\mathrm{ccm}}$ der Bakterienaufschremmung gefüllt. Eins dieser Gläschen wurde mit derselben Menge sterilen Wassers versetzt und hiervon die Controlculturen durch Ueberimpfen ron 3 Desen angelegt, sowonl bei Beginn als nach Beendigung des Versuches, ferner 24 und 48 Stunden später, um so die Möglichkeit, dass die Bakterien schon durch den Aufenthalt im Wasser geschädigt werden könnten, zu widerlegen. $\mathrm{Zu}$ den übrigen Aufschwemmungen wird genau die gleiche Menge des Desinficiens zugesetzt in einer Concentration, die zweimal so stark ist als diejenige, bei welcher die Prüfung des Mittels rorgenommen werden soll. Nach verschiedenen Zeiträumen wurden nun je 3 Platinösen der Suspension auf den Nährboden (Bouillon oder Agar) übertragen. Die Prüfung der Desinfectionskraft geschah bei Zimmertemperatur, sofern dies nicht anders angegeben ist. Die geimpften Gläschen kamen sogleich in den Brütofen, der auf $37.5{ }^{\circ} \mathrm{C}$. eingestellt war. Nach 2 oder 3 Tagen 
wurde constatirt, ob Wachsthum eingetreten war, und falls es sich um Agarröhrchen handelte, wie zahlreich die Culturen sich entwickelt hatten. Gewöhnlich blieben die Reagensgläschen noch etwa 4 bis 5 Tage im Brütofen und wurden dann noch 14 Tage bei Zimmertemperatur stehen gelassen; die Beobachtungsdauer betrug 3 Wochen.

Ich bemerke ausdrücklich, dass ich mich in keinem Falle damit begnügt habe, das Aethylendiaminsilberphosphat allein auf seine bakterientödtende Kraft $\mathrm{zu}$ untersuchen, dass ich vielmehr gleichzeitig unter genau denselben Versuchsbedingungen eine entsprechende Arg. nitr.-Lösung prüfte, um so Vergleichswerthe mit einem bekannten Desinficiens zu erhalten. Fand ich z. B., dass das Silberphosphat in bestimmter Verdünnung den Staphylococcus pyogenes aureus in 10 Minuten, den Bacillus pyocyaneus in 20 Minuten abtödtet, so ist dies ein Zahlenwerth, mit dem wir nicht viel anfangen können, und der für die Praxis ron nicht sehr grosser Bedeutung ist, da er ja nur für die speciellen Bedingungen des Versuches Gültigkeit hat; Iehrt jedoch das Experiment, dass das betreffende Yittel den Staphylococcus 50 Minuten, den Erreger des blauen Eiters 40 Minuten früher abtödtet, als eine Höllensteinlösung ron gleichem Silbergehalt unter denselben Verhältnissen, so ist dies eine Thatsache, die uns sehr wohl eine Vorstellung von der Leistungsfähigkeit des Silberphosphats geben kann und ron orientirendem Werthe ist, da wir ja über die Wirksamkeit des Argentum nitricum durch die Erfahrung bereits unterrichtet sind. Von rerschiedenen Seiten ist auf die Wichtigkeit soleher Vergleichswerte hingewiesen worden, und bei den in der neueren Zeit angestellten Desinfectionsprüfungen sind bereits öfters Controlrersuche mit bekannten antiseptischen Mitteln vorgenommen worden.

Wie aus der oben mitgetheilten Versuchsanordnung ersichtlich ist, habe ich bei der Desinfectionsprüfung nicht die Concentration der Lösungen, wie dies gewöhnlich geschieht, sondern die Expositionsdauer verändert. Es geschah dies wesentlich aus 2 Gründen. Das zu prüfende Mittel war in erster Reihe für die Behandlung der Gonorrhoe bestimmt worden; da nun praktische Versuche gelehrt hatten, dass es sich hierzu in einer Concentration ron 1:4000 eignete, da stärkere Lösungen bereits erhebliche Reizerscheinungen hervorriefen, so schien es rathsam, die Desinfectionskraft der Silberlösung gerade in dieser praktisch rerwendbaren Verdünnung zu untersuchen. Ferner war es mit Hülfe dieser Versuchsanordnung am leichtesten möglich, gut vergleichbare Werthe bezüglich der Leistungsfähigkeit der Mittel zu erhalten, worauf - wie bereits betont - besonders grosser Werth gelegt wurde.

Es fragt sich nun, in wie weit die oben geschilderte Methode den strengen Anforderungen, welche heute an Desinfectionsrersuche gestellt 
werden, gerecht wird. In erschöpfender Weise sind die Hauptfehlerquellen bei derartigen Versucheu von Max Gruber in einem Vortrage „Ueber die Methoden der Prüfung von Desinfectionsmitteln" (7) zusammengefasst worden; aus seinen in diesem Sinne angestellten Ontersuchungen zieht er den Schluss, dass die meisten der bisher angewandten Methoden mit so bedeutenden Fehlerquellen behaftet sind, dass die damit gewonnenen Resultate kein Vertrauen verdienen. Im Folgenden will ich nun mit Berücksichtigung der von ihm aufgestellten Gesichtspunkte die von mir angewandte Methode auf ihre Brauchbarkeit prüfen.

Für's erste weist Gruber auf die Verschiedenheit der Resistenz der als Testobjecte benutzten Culturen hin, welche nicht nur für die Milzbrandsporen, sondern auch für den Staphylococcus pyogenes aureus besonders von Esmarch (8) nachgewiesen wurde.

Was diesen Punkt anbetrifft, so ist Folgendes zu erwähnen. Die Milzbrandsporen, mit welchen ich arbeitete, wurden auf ihre Widerstandsfähigkeit gegenüber 5 procent. Carbolsäure geprüft, wobei dieselbe sich als sehr beträchtlich erwies. Auch die übrigen Milkroorganismen wurden mit Bezug auf ihre Resistenz untersucht, da ja - wie erwähnt - in allen Fällen Parallelversuche mit einem bekannten Desinficiens veranstaltet wurden. Dies geschah sowohl mit einer Argent. nitr.-Iüsung $1: 4000$, als auch mit einer $1 / 4$ procentigen Cresollösung, zuweilen ausserdem noch mit einer verdünnten Sublimatlösung, so dass also die als Prufungsobjecte dienenden Culturen sehr genau auf ihre Widerstandsfähigkeit geprüft waren.

Zweitens wird die Forderung gestellt, dass die Mikroorganismen nach der Behandlung mit dem Desinfectionsmittel unter die günstigsten Lebensbedingungen gebracht werden. Es ist klar, dass andernfalls unrichtige Resultate sich ergeben müssen, indem die übertragenen Proben zwar geschwächt aber doch noch lebenstähig sein können und nur deshalb nicht zur Entwickelung kommen, weil ihnen die Wachsthumsbedingungen, wie z. B. Temperatur und Nährboden nicht zusagen. Aus diesem Grunde habe ich es vermieden, die Entwickelungsfähigkeit der übertragenen Aufschwemmung in Gelatine festzustellen, weil es mit Sicherheit constatirt ist, dass die Zimmertemperatur für die meisten hier in Betracht kommenden Mikroben ungünstiger ist als die Körpertemperatur. So hat z. B. Boer (9) bei seinen Ontersuchungen über die Leistungsfähigkeit mehrerer chemischer Desinfeetionsmittel gefunden, dass das Wachsthum in Gelatine zuweilen ausbleibt, obgleich die Bakterien noch nicht vollständig entwickelungsunfähig sind. Ich habe in vereinzelten Fällen, um die Zahl der lebensfähigen Keime zu bestimmen, in Gelatine übertragen und konnte hierbei die von Boer gemachte Beobachtung bestätigen, dass man zuweilen 
noch Wachsthum in Bouillon und in Agar bekommt zu einer Zeit, wo die Gelatineplatten bereits steril blieben. Ich habe daher die Uebertragung auf Agar oder auf Bouillon rorgenommen; bei den ersten Versuchen mit Bacillus prodigiosus, pyocyaneus und Staphylococeus aureus habe ich gleichzeitig Proben auf beide Nährböden überimpft, um zu erfahren, ob sich hierbei Unterschiede ergeben würden. Es stellte sich heraus, dass die Resultate häufig nicht gleich waren, und dass in mehreren Fällen in Bouillon das Wachsthum früher aufhörte, als bei Uebertragung auf Agar. Aus diesem Grunde habe ich bei den späteren Versuchen dás letztere Verfahren bevorzugt.

An dritter Stelle hebt Gruber eine Fehlerquelle hervor, auf welche zuerst $\mathrm{Koch}$ in der oben citirten Schrift die Aufmerksamkeit gelenkt, und deren Bedeutung in sehr überzeugender Weise Geppert dargelegt hat. Es handelt sich um die Mitübertragung von Spuren des Desinficiens auf die frischen Nährböden, wobei naturgemäss Entwickelungshemmung eintritt und fälschlich günstigere Resultate vortäuscht. Bekanntlich hat Geppert nachgewiesen, dass Milzbrandsporen, die einige Zeit dem Sublimat ausgesetzt waren, auf ganz schwach sublimathaltigem Nährboden nicht mehr zur Entwickelung kommen, und dass hierbei selbst ganz geringe Spuren in Betracht kommen. Mit Recht hat man in der neueren Zeit diesen Verhältnissen bei Desinfectionsversuchen besondere Aufmerkkeit geschenkt und die hieraus resultirende Fehlerquelle nach Möglichkeit zu vermeiden gesucht. Es ist nun klar, dass der Versuchsfehler um so geringer wird, je schwächer die antiseptische Kraft des zu prüfenden Mittels ist, je weniger von der Flüssigkeit übertragen wird und je grösser die Menge des Nährbodens ist, in welchen die Keime überimpft werden, endlich ist es zweckmässig die gelungene Desinfection nicht bei Zimmertemperatur, sondern im Brütofen zu bestimmen, da dann der entwiclielungshemmende Einfluss des dem Nährboden beigemischten Desinficiens erwiesenermassen weniger zur Geltung kommt. In wie weit kommt nun der in Rede stehende Fehler bei der von mir angewandten Versuchsanordnung in Betracht? Es ist unzweifelhaft, dass bei dem oben geschilderten Verfahren Spuren der antiseptischen Substanz in den frischen Nährboden gelangten; indessen beträgt die Mlenge derselben nur drei Platinösen, ${ }^{1}$ ist also sehr gering im Vergleich mit den $10^{\mathrm{cem}}$ Bouillon, in welchen sie sich vertheilt; ferner ist die Entwickelungshemmung bei den hier in Betracht kommenden Mitteln nicht so erheblich wie beim Sublimat,

1 Die Gewichtsmenge der einer Platinöse anhaftenden Flüssigkeit betrug an-

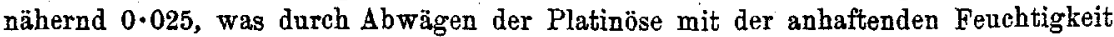
und nach dem Ausglühen bestimmt warde. 
und schliesslich wurden die Bouillon- bezw. Agar-Röhrchen ${ }^{1}$ unmittelbar nach der. Impfung in den Brütofen gestellt.

Trotz aller dieser Gründe, die geeignet erscheinen, die Bedeutung des besprochenen Einwandes einzuschränken, lässt sich doch nicht leugnen, dass der Versuchsfehler thatsächlich besteht, und nicht eher war die Methode als einwandsfrei und vollkommen zu betrachten, bis es gelang die Fehlerquelle ganz auszuschalten oder aber nachzuweisen, dass sie zu gering ist, als dass durch dieselbe die Versuchsergebnisse beeinflusst werden könnten. Die von Geppert angegebene Methode der chemischen Unschädlichmachung konnte hierbei keine Anwendung finden, da die complicirten Verbindungen, welche zu prüfen waren, sich auf chemischem Wege nicht in indifferente Körper überführen liessen. Ich habe daher versucht die Uebertragung von Desinficiens durch Anwendung eines besonderen Verfahrens zu vermeiden und mit Hülfe desselben den Nachweis zu liefern, dass bei der geschilderten Versuchsanordnung der betreffende Fehler die Genauigkeit der Resultate nicht merklich beeinträchtigt und somit ausser Acht gelassen werden kann. Ich gehe hier auf diesen Punkt nicht ein, da ich mich später mit der Lösung dieser Frage genauer beschäftigen werde.

Eine andere Unzulänglichkeit der meisten Desinfectionsversuche besteht nach Gruber darin, dass die Anssaaten aus den Desinfectionsgemischen zu kurze Zeit beobachtet werden. Er verlangt, dass die Beobachtung sich auf 8 bis 10 Tage erstrecke, da bisweilen noch mehrere Tage nach der Ueberimpfung Wachsthum erfolge. Dieser Anforderung ist bei den vorliegenden Versuchen vollständig Genüge geleistet worden, da - wie oben erwähnt - die geimpften Gläschen 3 Wochen lang auf etwaiges Wachsthum controlirt wurden. Ich habe gleichfalls in mehreren Fällen Entwickelung von Colonieen noch auffallend spät, z. B. 3 oder 4 Tage nach der Uebertragung, gesehen und dies an den betreffenden Stellen besonders bemerkt.

Fünftens wird verlangt, dass das Medium angegeben wird, in welchem sich die Mikroorganismen bei der Finwirkung des Desinficiens befinden. Dies geschah in sämmtlichen Fällen; es stelite sich hierbei heraus, dass in der That die Resultate sehr verschieden waren, je nachdem die

\footnotetext{
1 Man sollte annehmen, dass beim Uebertragen auf Agargläschen die entwickelungshemmende Wirkung des Desinficiens störender sein müsste, als bei Verwendung von Bouillon, wobei die antiseptische Flüssigkeit sich besser vertheilen kann. Dies war jedoch nicht der Fall, was wohl dadurch zu erklären ist, dass die Flüssigkeit auf der schrägen Agarfläche grossentheils abfloss, während die Bakterien an dem Nährboden hafteten.
} 
Bakterien in Wasser, Bouillon, Hydrocelenflüssigkeit oder Blutserum abzutödten waren.

Ebenso ist es nothwendig, dass die Temperatur angegeben wird, bei welcher die Desinfectionsprüfung stattfindet, da bekanntlich für mehrere Desinficientien eine Zunahme der keimtödtenden Kraft bei erhöhter Temperatur nachgewiesen ist. Die Prüfung der Aethylendiaminpräparate geschah bei $20^{\circ} \mathrm{C}$; nur in einem Falle wurde ein gleichzeitiger Versuch bei einer Temperatur von $37.5^{\circ}$ angestellt, wobei sich deutlich eine energischere Desinfectionswirkung constatiren liess.

Ferner macht Gruber darauf aufmerksam, dass ungleichmässige Vertheilung der Mikroorganismen die Sicherheit der Ergebnisse beeinträchtige. Mit Bezug auf diesen Punkt ist bereits oben erwähnt, dass die Bakteriensuspensionen sorgfältig filtrirt und geschüttelt wurden, und dass das Desinfectionsmittel erst dann zugesetzt wurde, nachdem durch mikroskopische Untersuchung festgestellt war, dass die Bakterien keine grösseren Conglomerate mehr bildeten.

Wie aus dem bisher Gesagten hervorgeht, sind die strengen Anforderungen, welche Gruber an eine richtige Desinfectionsprüfung stellt, durchaus erfüllt, und die Versuchsfehler, welche er anführt, nach Möglichkeit vermieden.

Es bleibt schliesslich noch übrig mit einigen Worten auf die Reichlichkeit der zu den Versuchen benützten Aufschwemmungen einzugehen, da dieselbe unzweifelhaft von sehr erbeblichem Einfluss auf die Resultat, ist. In der neueren Litteratur findet man häufig die Thatsache angedeutet, dass es keineswegs gleichgültig ist, ob sehr viele oder nur wenige Mikroorganismen zu vernichten sind, dass eine sehr reichliche Aufschwemmung viel schwieriger zu desinficiren ist als eine spärliche. Ich werde später mehrere Versuche anführen, welche die Richtigkeit dieser Behauptung völlig bestätigen, und versuchen, die Erklärung für diese Thatsache zu geben. Jedenfalls ist es rathsam bei der Desinfectionsprüfung möglichst reichliche Bakterienemulsionen anzuwenden und genau die Herstellung derselben anzugeben, da andernfalls die gewonnenen Resultate erheblich an Werth verlieren würden. Wie die zu unseren Experimenten verwandten Aufschwemmungen hergestellt wurden, ist bereits oben auseinandergesetzt und wird besonders angegeben werden, falls ron dem gewöhnlichen Modus abgewichen wurde. Was die Reichlichkeit unserer Suspensionen betrifft, so wurde dieselbe nach Gruber's Vorgange so geprüft, dass ein Tropfen einer 2000 fachen Verdünnung mit Gelatine zur Platte ausgegossen, und die Zahl der darin enthaltenen Keime bestimmt wurde. Es zeigte sich z. B. bei einer Aufschwemmung von Bacillus prodigiosus, soweit die bald eintretende Verflüssigung der Gelatine eine genaue 
Zählung überhaupt gestattete, dass ein Tropfen der 2000 fachen Verdünnung 75600 Keime enthielt. Auf einer in derselben Weise von einer Typhusaufschwemmung hergestellten Platte wurden 96764 Colonieen gezählt.

Die verwandten Suspensionen waren somit ungemein reichlich, so dass eine einzige Oese stets viele Millionen lebensfähiger Individuen enthielt.

Endlich möchte ich noch bemerken, dass die Nährböden, in welchen die gelungene Desinfection geprüft wurde (Bouillon und Agar), ganz schwach alkalisch reagirten; ich führe dies an, weil nach Boer die Beschaffenheit des Nährbodens (besonders die Reaction), in welchem die Lebensfähigkeit der übertragenen Proben geprüft wird, für die Resultate nicht ohne Bedeutung ist.

Beror ich nun zur Mitteilung der mit Hülfe der geschilderten Methode gewonnenen Zahlenwerthe übergehe, will ich noch kurz 2 Versuche erwähnen, welche sich auf die entwickelungshemmende Wirkung des Aethylendiaminsilberphosphats beziehen.

Wachsthumsbehinderung durch Zusatz ron Aetbylendiaminsilberphosphat 1:10000 und 1:50000 zum Agar.

Von drei Tage alten Culturen auf gewöhnlichem schräg erstarrten Agar werden drei Oesen verstrichen auf Agar ohne Zusatz (je drei Röhrchen als Controlculturen), zugleich auf demselben Nährboden, der Aethylendiaminsilberphosphat 1:10000 enthielt und zum Vergleich auf Agar, dem Arg. nitr. von demselben Silbergehalte zugesetzt war. Die Gläschen blieben drei Tage lang im Brütofen. Sämmtliche Controlculturen hatten sich sehr reichlich entwickelt. Dagegen zeigten sowohl auf dem Agar mit Silberphosphat als auch mit Arg. nitr. 1:10000 kein Wachsthum folgende Balsterien: Bacillus pyocyaneus, Staphylococorrs pyogenes aureus, Diplococcus urethrae, Choleraspirillen, Typhusbacillen, Milzbrandbacillen mit Sporen und Micrococcus tetragenus. Nur Bacillus prodigiosus zeigte auf den mit den Silbersalzen versetzten Agarröhrchen deutliches, jedoch erheblich vermindertes Wachsthum. Genau derselbe Versuch wurde vorgenommen mit Agar, dem die beiden Argentumverbindungen in einer Verdünnung von $1: 50000$ beigemischt waren. Es wurde ebenfalls nirgends Wachsthum beobachtet ausgenommen bei Bac. prodigiosus.

Ich komme nun zur Prüfung der Desinfectionstraft des Aethylendiaminsilberphosphats gegenüber verschiedenen Mikroorganismen.

Desinfectionsversuche mit Bacillus prodigiosus.

In etwa $10 \mathrm{~cm}$ sterilen Wassers werden von vier Agargläschen die Prodigiosusculturen, welche bei Zimmertemperatur drei Tage lang reichlich gewachsen waren, mit der Platinöse übertragen. In der oben geschilderten Weise wird nun die Aufschwemmung durch Schütteln und Filtriren mit Glas- 
wolle so lange behandelt, bis durch mikroskopische Untersuchung eine genügende Vertheilung der Keime constatirt war. Von dieser sehr trüben, röthlich gefärbten Emulsion werden nun je $3^{\mathrm{cem}}$ in drei sterile Reagensgläschen gefüllt, in das erste Glas die gleiche Menge sterilen Wassers, in das zweite 3 can Arg. nitr. 1:2000 und in das dritte ebensoviel Aethylendiaminsilberphosphat von demselben Silbergehalt zugesetzt, so dass von diesem Augenblicke an die Prodigiosuskeime dem Desinficiens in einer Concentration von 1:4000 exponirt waren. Glas I diente zur Herstellung der Controlculturen, Glas II und III zur Ueberimpfung von je drei Oesen auf schräg erstarrtes Agar nach verschiedenen Zeiträumen (jedesmal zwei Gläschen). Die so geimpften Röhrchen wurden sogleich in den Brütofen gestellt und nach zwei Tagen bei Zimmertemperatur stehen gelassen, wobei sich bei den angegangenen Colonieen um das farblose Centrum ein rothel Ring bildete. In Folge dieser Versuchsanordnung war einerseits der oben auseinandergesetzte Vortheil vorhanden, dass die Lebensfähigkeit der übertragenen Proben bei Körpertemperatur geprüft wurde, andererseits war es möglich an der später stattfindenden Farbstoffbildung die Prodigiosusculturen als solche zu erkennen und Verunreinigungen auszuschliessen.

Das Ergebniss des Desinfectionsversuches war folgendes:

Aufschwemmung von Prodigiosusbacillen in sterilem Wasser.

\begin{tabular}{|c|c|c|c|c|c|}
\hline Ueberimpfung nach: & 2 Min. & 5 Min. & 10 Min. & 20 Min. & 30 Min. \\
\hline Argentum nitricum $1 / 4000$ & $\begin{array}{l}\text { sehr } \\
\text { reichlich }\end{array}$ & desgl. & desgl. & reichlich & $\begin{array}{l}\text { sehr zahlr. } \\
\text { einz. Col. }\end{array}$ \\
\hline $\begin{array}{l}\text { Aethylendiaminsilber- } \\
\text { phosphat } 1 / 4000\end{array}$ & $\begin{array}{l}\text { zahlr. ver- } \\
\text { einz. Col. }\end{array}$ & \begin{tabular}{|c} 
vereinzelte \\
Colonieen
\end{tabular} & $\begin{array}{l}\text { spärliche } \\
\text { Colonieen }\end{array}$ & 0 & 0 \\
\hline Ueberimpfung nach: & 45 Min. & 1 Std. & $11 / 4$ Std. & $11 / 2$ Std. & 2 Std. \\
\hline Argentum nitricum $1 / 4000$ & $\begin{array}{l}\text { sehr zahlr. } \\
\text { einz. Col. }\end{array}$ & $\begin{array}{l}\text { spärl. einz. } \\
\text { Colonieen }\end{array}$ & desgl. & 0 & 0 \\
\hline $\begin{array}{l}\text { Aethylendiaminsilber- } \\
\text { phosphat } 1 / 4000\end{array}$ & 0 & 0 & 0 & 0 & 0 \\
\hline
\end{tabular}

Als derselbe Versuch wiederholt wurde, und die Uebertragung nach verschiedener Expositionsdauer nicht nur auf Agar, sondern auch in Bouillon vorgenommen wurde, ergaben sich im ersteren Falle dieselben Resultate; die Bouillonröhrchen dagegen blieben bei Ueberimpfung aus der Aufschwemmung mit Arg. nitr. bereits 15 Minuten früher steril, bei der Desinfection mit dem Aethylendiaminpräparat 10 Minuten früher als die entsprechenden Agarröhrchen; die Uebertragung in Bouillon lieferte also die ungenaueren Resultate.

Ein gleicher Desinfectionsversuch wurde nun angestellt mit einer Aufschwemmung von Prodigiosuskeimen in Nährbouillon, welche in derselben Weise wie oben hergestellt wurde. 
Über D. DESINFECTIONSWERTH D. AEThyLENDIAMLNSILbeRPhosphats. 209

Aufschwemmung von Prodigiosusbacillen in Nährbouillon.

\begin{tabular}{|c|c|c|c|c|c|}
\hline Ueberimpfung nach: & 5 Min. & $10 \mathrm{Min}$. & 20 Min. & $30 \mathrm{Min}$. & $45 \mathrm{Min}$. \\
\hline Argentum nitricum $1 / 4000$ & $\begin{array}{l}\text { sehr } \\
\text { reichlich }\end{array}$ & desgl. & desgl. & desgl. & $\begin{array}{l}\text { zahlreiche } \\
\text { einz. Col. }\end{array}$ \\
\hline $\begin{array}{l}\text { Aethylendiaminsilber- } \\
\text { phosphat } 1 / 4000\end{array}$ & $\begin{array}{l}\text { sehr } \\
\text { reichlich }\end{array}$ & reichlich & 0 & 0 & 0 \\
\hline Ueberimpfung nach: & 1 Stà. & $11_{4}$ Std. & $1 \%$ Std. & 2 Std. & \\
\hline Argentum nitricum $1 / 4000$ & $\begin{array}{l}\text { vereinzelte } \\
\text { Colonieen }\end{array}$ & desgl. & $\begin{array}{c}3 \text { bis } 5 \\
\text { Colonieen }\end{array}$ & 0 & \\
\hline $\begin{array}{c}\text { Aethylendiaminsilber- } \\
\text { phosphat }{ }^{1} y_{4000}\end{array}$ & 0 & 0 & 0 & 0 & \\
\hline
\end{tabular}

Es wurde ferner eine Aufschwemmung von Prodigiosuskeimen in steriler Hydrocelenflüssigkeit hergestellt, und zu je 3 cm derselben gleiche Mengen der beiden Desinficientien (1:2000), und zum Vergleich Sublimat in derselben Concentration hinzugefügt. Beim Zusatz des Arg. nitr. sowohl als auch des Silberphosphats wurde die gelbliche, durchscheinende Flüssigkeit sehr trübe. Während jedoch die erste Lösung nach wenigen Minuten den von der Reduction des Silbersalzes herrührenden Farbenton zeigte, behielt die zweite Lösung ihre hellgelbe Farbe viel länger (etwa $1 / 2$ Stunde) bei, ehe auch hier die Reduction des Silbers eintrat. Beim Zusatz der Sublimatlösung zeigte die Hydrocelenflüssigkeit nur ganz unbedeutende Trübung, welche längere Zeit unverïndert bestehen blieb.

Aufschwemmung von Prodigiosusbacillen in Hydrocelenflüssigkeit.

\begin{tabular}{|c|c|c|c|c|c|c|}
\hline Ueberimpfung nach: & 10 Min. & 20 Min. & $30 \mathrm{Min}$ & 45 Min. & 1 Std. & $11 / 4$ Std. \\
\hline $\begin{array}{l}\text { Argentum nitr. } 1 / 4000 \\
\text { Aethylendiamin- } \\
\text { Silberphosphat } 1 / 4000 \\
\text { Sublimat } 1 / 4000\end{array}$ & $\begin{array}{l}\text { s. reichl. } \\
\text { s. reichl. } \\
\text { s. reichl. }\end{array}$ & $\begin{array}{l}\text { desgl. } \\
\text { desgl. } \\
\text { reichlich }\end{array}$ & $\begin{array}{c}\text { desgl. } \\
\text { reichlich } \\
\text { spärlich }\end{array}$ & $\begin{array}{c}\text { desgl. } \\
\text { desgl. } \\
0\end{array}$ & $\begin{array}{l}\text { desgl. } \\
\text { desgl. } \\
0\end{array}$ & $\begin{array}{c}\text { desgl. } \\
\text { vereinzelt. } \\
\text { Colonieen } \\
0\end{array}$ \\
\hline Ueberimpfung nach: & $11 / 2 \mathrm{Std}$ & 2 Std. & $2^{1} / 2$ Std. & 3 Std. & $3^{1 / 2}$ Std. & $4-6$ Std. \\
\hline $\begin{array}{l}\text { Argentum nitr. 1/4000 } \\
\text { Aethylendiamin- } \\
\text { Silberphosphat 1/4000 } \\
\text { Suplimat } 11\end{array}$ & $\begin{array}{c}\text { s. reichl. } \\
0\end{array}$ & $\begin{array}{c}\text { desgl. } \\
0\end{array}$ & $\begin{array}{c}\text { z. einz.Col. } \\
0\end{array}$ & $\begin{array}{c}\text { desgl. } \\
0\end{array}$ & $\begin{array}{c}\text { spärl. Col. } \\
0\end{array}$ & $\begin{array}{l}0 \\
0\end{array}$ \\
\hline Sublimat 1/4000 & 0 & 0 & 0 & 0 & 0 & 0 \\
\hline
\end{tabular}

Bei Verwendung einer Aufschwemmung von Prodigiosusbacillen in menschlichem Blutserum zu einem gleichen Versuch ergab sich, dass nach 2 Stunden weder Arg. nitr. noch Aethylendiaminsilberphosphat Zeitschr. \&. Hygiene. XVI. 
1: 4000 die Keime getödtet hatte, dass allerdings im letzteren Falle die Culturen viel spärlicher wuchsen.

Aus den angeführten Resultaten geht mit grosser Deutlichkeit hervor, wie bedeutend der Einfluss des Mediums ist, in welchem die Bakterien abzutödten sind. Es erklärt sich das wohl so, dass die Silberlösungen mit den Salzen (besonders Chlornatrium) der Nährbouillon und dem Eiweiss der Hydrocelenflüssigkeit und des Blutserums chemische Verbindungen eingehen, welche weniger wirksam sind als die ursprünglichen Lösungen. Man könnte vielleicht noch annehmen, dass in sterilem Wasser die Mikroorganismen besonders leicht zu vernichten sind, weil hier gewissermassen zwei schädliche Momente gleichzeitig einwirken, erstens das Desinficiens, zweitens die Entziehung jeder Nährsubstanz; indessen scheint der letztere Punkt ron ganz untergeordneter Bedeutung zu sein, wenn man bedenkt, dass z. B. die Prodigiosuskeime in sterilem Wasser mehrere Tage lang ihre Entwickelungsfähigkeit unverändert beibehalten. - In welchem Medium nun auch die Bacillen vermichtet werden sollten, stets war die Desinfectionskraft des Aethylendiaminsilberphosphats derjenigen einer entsprechenden Argentum nitricum-Lösung bei weitem überlegen.

Prüfung der Desinfectionskraft einer Aethylendiaminsilberphosphat- und Arg. nitr.-Lösung 1:4000 gegenüber Bacillus pyocyaneus.

Die zur Aufschwemmung rerwandten Culturen waren 2 Tage lang bei $37.5^{\circ} \mathrm{C}$. gewachsen; die Bakteriensuspension musste zweimal filtrirt und̉ längere Zeit geschüttelt werden, ehe eine gleichmässige Vertheilung erreicht war.

Aufschwemmung von Bacillus pyocyaneus in Wasser.

\begin{tabular}{|c|c|c|c|c|c|}
\hline Ueberimpfung nach: & 2 Min. & 5 Min. & 10 Min. & 20 Min. & 30 Min. \\
\hline Argentum nitricum $1 / 4000$ & reichlich & desgl. & desgl. & desgl. & spärlich \\
\hline $\begin{array}{l}\text { Aethylendiamin- } \\
\text { Silberphosphat } 1 / 4000\end{array}$ & reichlich & spärlich & desgl. & 0 & 0 \\
\hline Ueberimpfung nach: & 45 Min. & $1 \mathrm{Std}$. & $11 / 4 \mathrm{Std}$. & $11 / 2$ Std. & \\
\hline Argentum nitricum $1 / 4000$ & $\begin{array}{l}\text { vereinzelt } \\
\text { Colonieen }\end{array}$ & $\begin{array}{l}\text { spärl. einz. } \\
\text { Colonieen }\end{array}$ & 0 & 0 & \\
\hline $\begin{array}{l}\text { Aethylendiamin- } \\
\text { Silberphosphat }\left.\right|_{4000}\end{array}$ & 0 & 0 & 0 & 0 & \\
\hline
\end{tabular}


ÜBER D. DESLNFECTIONSWERTH D. AETHYLENDIAMINSILBERPHOSPHATS. 211

Als die Lebensfähigkeit der übertragenen Proben anstatt auf Agar in $\left(10^{\mathrm{cem}}\right)$ Nährbouillon geprüft wurde, ergab sich das gleiche Resultat, nur zeigten die aus der mit Arg. nitr. versetzten Aufsehwemmung entnommenen Keime bereits nach 60 Minuten keine Entwickelung mehr, während sie auf Agar noch wuchsen.

Im menschlichen Blutserum waren die Pyocyaneusbacillen wiederum viel schwerer zu vernichten, als in wässriger Aufschwemmung. Das Serum wurde vorher, um die antiparasitäre Eigenschaft desselben zu beseitigen, nach R. Stern's (11) Vorgang $1 / 2$ Stunde lang auf $60^{\circ} \mathrm{C}$. erwärmt; gleichzeitig wurde auch eine Sublimatlösung 1:4000 geprüft, wobei dieselbe ebenso wie in dem Versuch mit Prodigiosus das Silberphosphat um ein Geringes, das Arg. nitr. um ein Bedeutendes an Wirksamkeit übertraf.

Aufschwemmung von Bacillus pyocyaneus in Blutserum.

\begin{tabular}{|c|c|c|c|c|c|c|}
\hline Ueberimpfung nach: & 5 Min. - 1 Std. & $11 / 4$ Std. & $11 / 2$ Std. & $1^{3} / 4$ Std. & 2 Std. & $2^{1 / 2}$ Std. \\
\hline Argentum ditr. 1/4000 & & desgl. & desgl. & desgl. & desgl. & $\begin{array}{c}\text { zahlr. } \\
\text { einz.Col. }\end{array}$ \\
\hline $\begin{array}{l}\text { Aethylendiamin- } \\
\text { Silberphosphat }{ }^{1 / 40}\end{array}$ & reichl. & spärlich & einz.Col. & 0 & 0 & 0 \\
\hline Sublimat $1 / 4000$ & reichl. & einz.Col. & 0 & 0 & 0 & 0 \\
\hline
\end{tabular}

Bei dem nächsten Versuche mit Staphylococcus pyogenes aureus war dagegen die Desinfectionskraft des Silberphosphats nicht nur derjenigen des Arg. nitr., sondern auch des Sublimats sehr überlegen. Die Uebertragung auf Nährbouillon ergab wiederum ungenauere Resultate.

Aufschwemmung von Staphylococeus pyogenes aureus in Wasser.

\begin{tabular}{|c|c|c|c|c|c|}
\hline Ueberimpfung nach: & 2 Min. & j Min. & 10 Min. & 20 Min. & $30 \mathrm{Min}$. \\
\hline $\begin{array}{l}\text { Argentum nitricum } 1 / 4000 \\
\text { Aethylendiamin- } \\
\text { Silberphosphat } 1 / 4000 \\
\text { Sublimat } 1 / 4000\end{array}$ & $\begin{array}{l}\text { s. reichl. } \\
\text { reichlich } \\
\text { s. reichl. }\end{array}$ & $\begin{array}{l}\text { desgl. } \\
\text { zahlreiche } \\
\text { einz. Col. } \\
\text { reichlich }\end{array}$ & $\begin{array}{c}\text { reichlich } \\
0 \\
\text { desgl. }\end{array}$ & $\begin{array}{l}\text { desgl. } \\
0 \\
\text { desgl. }\end{array}$ & $\begin{array}{l}\text { desgl. } \\
0 \\
\text { desgl. }\end{array}$ \\
\hline Ueberimpfung nach: & $45 \mathrm{Min}$. & 1 Std. & $11 / 4$ Std. & $11 / 2-3$ Std. & \\
\hline Argentum nitricum $1 / 4000$ & desgl. & 0 & 0 & 0 & \\
\hline $\begin{array}{c}\text { Aethylendiamin- } \\
\text { Silberphosphat 1/4000 }\end{array}$ & 0 & 0 & 0 & 0 & \\
\hline Sublimat $1 / 4000$ & desgl. & 0 & 0 & 0 & \\
\hline
\end{tabular}

Die Prüfung der Desinfectionslraft der Silberlösungen gegenüber Choleraspirillen ergab, dass schon nach 2 Minuten Abtödtung erfolgt war; auch als derselbe Versuch mit Aethylendiaminsilberphosphat und 
Arg. nitr. 1:10000 wiederholt wurde, zeigten schon die nach 2 Minuten übertragenen Proben keine Entwickelung, während die Controlculturen reichliches Wachsthum aufwiesen, selbst als die Ueberimpfung nach 24 Stunden vorgenommen wurde.

Ebenso war bei einer reichlichen Aufschwemmung von Diphtheriebacillen, sowie von Sarcina aurantiaca die Abtödtung durch die beiden Argentumsalze $(1: 4000)$ bereits nach 2 Minuten erfolgt. In beiden Fällen wuchsen die Controlculturen sehr reichlich.

Es wurde ferner die Desinfectionskraft des Aethylendiaminsilberphosphats mit Bezug auf den milchweissen Diplococcus urethrae geprüft, welcher aus einer normalen männlichen Harnröhre gezüchtet worden war.

Aufschwemmung ron Diplococcus urethrae in sterilem Wasser.

\begin{tabular}{|c|c|c|c|c|c|}
\hline Ueberimpfung nach: & 2 Min. & 5 Min. & 10 Min. & 20 Min. & 30 Min. \\
\hline Argentum nitricum $1 / 4000$ & s. reichl. ! & desgl. & desgl. & $\begin{array}{l}\text { zahlreiche } \\
\text { einz. Col. }\end{array}$ & desgl. \\
\hline $\begin{array}{l}\text { Aethylendiamin- } \\
\text { Silberphosphat 1/4000 }\end{array}$ & $\begin{array}{l}\text { zahlreiche } \\
\text { einz. Col. }\end{array}$ & desgl. & $0^{1}$ & $0^{-}$ & 0 \\
\hline Ueberimpfung nach: & 45 Min. & 1 Std. & $1 \%$ Std. & $11 / 2$ Std. & \\
\hline Argentum nitricum $1 / 4000$ & $\begin{array}{l}\text { zahlreiche } \\
\text { einz. Col. }\end{array}$ & $\begin{array}{l}\text { spärliche } \\
\text { Colonieen }\end{array}$ & 0 & 0 & \\
\hline $\begin{array}{l}\text { Aethylendiamin- } \\
\text { Silberphosphat } 1 / 4000\end{array}$ & 0 & 0 & 0 & 0 & \\
\hline
\end{tabular}

Bei Verwendung von menschlichem Blutserum zur Aufschwemmung erfolgte auch hier die Abtödtung erheblich später. Auffallend war, dass in mehreren Fällen die Reagensgläschen Anfangs steril blieben, und dass erst nach 3 Tagen Wachsthum bemerkbar wurde.

Aufschwemmung von Diplococcus urethrae in menschlichem Blutserum.

\begin{tabular}{|c|c|c|c|c|c|}
\hline Ueberimpfung nach: & 5 Min. & $10 \mathrm{Min}$. & $20 \mathrm{Min}$. & $30 \mathrm{Min}$. & $45 \mathrm{Min}$. \\
\hline Argentum nitricum $1 / 4000$ & s. reichl. & desgl. & desgl. & desgl. & desgl. \\
\hline $\begin{array}{l}\text { Aethylendiamin- } \\
\text { Silberphosphat } 1 / 4000\end{array}$ & s. reichl. & reichlich & $\begin{array}{l}\text { zahlreiche } \\
\text { einz. Col. }\end{array}$ & desgl. & $\begin{array}{l}\text { vereinzelte } \\
\text { Colonieen }\end{array}$ \\
\hline Sublimat $1 / 4000$ & s. reichl. & desgl. & desgl. & desgl. & desgl. \\
\hline
\end{tabular}

1 Nach 3 Tagen fand noch Entwickelung einzelner Colonieen statt. 
Über D. DesinfeCtionsWeRth D. AEThylendiaminsilberphosphats. 213

(Fortsetzung.)

\begin{tabular}{|c|c|c|c|c|c|c|}
\hline Ueberimpfung nach: & 1 Std. & 11/4 Std. & $1 \%$ Std. & 2 Std. & $21 / 2$ Std. & 3 Std. \\
\hline Argentum nitr. $1 / 4000$ & reichlich & desgl. & desgl. & $\begin{array}{l}\text { zahlreiche } \\
\text { einz. Col. }\end{array}$ & desgl. & desgl. \\
\hline $\begin{array}{l}\text { Aethylendiamin- } \\
\text { Silberphosphat } 1 \%_{4000}\end{array}$ & $\begin{array}{l}\text { spärliche } \\
\text { Colonieen }\end{array}$ & $0^{1}$ & $0^{1}$ & 0 & 0 & 0 \\
\hline Sublimat $1 / 4000$ & $\begin{array}{l}\text { zahlreiche } \\
\text { einz. Col. }\end{array}$ & $\begin{array}{l}\text { spärliche } \\
\text { einz. Col. }\end{array}$ & 01 & $0^{1}$ & 0 & 0 \\
\hline
\end{tabular}

Bei der Desinfectionsprüfung der Silberlösungen gegenüber Ty phusbacillen wurde der Versuch nicht nur bei Zimmertemperatur, sondern auch bei $37.5^{\circ} \mathrm{C}$. vorgenommen. - Bekanntlich hat Henle darauf hingewiesen, dass die Leistungsfähigkeit von Desinficientien (z. B. Sublimat, Creolin und Carbolsäure) durch Temperaturunterschiede erheblich beeinflusst wird. Seine Angaben sind ebenso für zahlreiche andere keimtödtende Flüssigkeiten bestätigt worden. Dass auch das Argentum nitricum bei böherer Temperatur energischere Wirkung entfaltet, ist aus den beiden folgenden Tabellen ersichtlich. Die beiden Versuche wurden unter sonst vollständig gleichen Bedingungen mit derselben Bacillenaufschwemmung angestellt, nur dass im ersten Falle die Desinfectionsprüfung bei $20^{\circ} \mathrm{C}$, im zweiten bei $37.5^{\circ} \mathrm{C}$. geschah.

Aufschwemmung von (2 Tage alten) Typhusculturen in Wasser (Desinfectionsprüfung bei $20^{\circ} \mathrm{C}$.)

\begin{tabular}{c||c|c|c|c|c|c|c|c}
\hline \hline Ueberimpfung nach: & 2 Min. & 5 Min. & 10 Min. & 20Min. & 30 Min. & 45 Min. & 1 Std. & $11_{4}-3$ St. \\
\hline Argentum nitr. 1/4000 & $\begin{array}{c}\text { sehr } \\
\text { reichl. }\end{array}$ & desgl. & reichl. & desgl. & zahlreiche & 0 & 0 & 0 \\
einz. Col. & & 0 & 0 & 0 & 0 \\
$\begin{array}{c}\text { Aethylendiamin- } \\
\text { Silberphosphat 1/4000 }\end{array}$ & 0 & 0 & 0 & 0 & 0 & 0 & 0
\end{tabular}

Gleicher Versuch bei $37 \cdot 5^{\circ} \mathrm{C}$.

\begin{tabular}{|c|c|c|c|c|c|c|c|}
\hline Argentum nitr. ${ }^{1 / 4000}$ & reichl. & desgl. & $\begin{array}{l}\text { zahlr. } \\
\text { Colon }\end{array}$ & 0 & 0 & 0 & 0 \\
\hline $\begin{array}{l}\text { Aethylendiamin } \\
\text { Silberphosphat } 1 / 4000\end{array}$ & 0 & 0 & 0 & 0 & 0 & 0 & 0 \\
\hline
\end{tabular}

Die Arg. nitr.-Lösung tödtete also die Typhuskeime bei $37.5^{\circ} \mathrm{C}$. etwa um 25 Minuten früher ab, als bei einer Temperatur von $20^{\circ} \mathrm{C}$.

Desinfectionsprüfung gegenüber Micrococeus tetragenus.

Eine Aufschwemmung von Micrococcus tetragenus in sterilem Wasser wurde durch die alkalische Silberlösung ebenso wie durch Arg. nitr. in

1 Nach 3 Tagen fand noch Entwickelung einzelner Colonieen statt. 
einer Verdünnung von 1:4000 bereits nach 2 Minuten getödtet, so dass bei diesem Versuch sämmtliche Gläschen steril blieben; die Controleulturen wuchsen sehr reichlich. Bei einer Einwirkung der beiden Desinfectionsflüssigkeiten im Verhältnis von 1:10000 wuchsen nach 2 Minuten spärliche Culturen; nach 5 Minuten war kein Wachsthum mehr za beobachten.

Gleichzeitig wurde auch die Prüfung der Virulenz der Mikroorganismen vorgenommen und zwar in der Weise, dass aus den mit dem Desinficiens versetzten Aufschwemmungen nach verschiedener Expositionsdauer 3 Platinösen weissen Mäusen in eine Hauttasche oberhalb der Schwanzwurzel eingeimpft wurden. Der Controlversuch wurde so angestellt, dass aus der mit gleichen Theilen Wassers versetzten Tetragenusaufschwemmung nach Beendigung des Desinfectionsversuches eine weisse Maus 3 Platinösen subcutan erhielt; das Thier starb am sechsten Tage. Milz sehr stark geschwollen mit weisslichen Herden; im Strichpräparat zahlreiche Tetragenusmikrokokken; aus der Milz angelegte Culturen zeigen charakteristisches Wachsthum. Aus den mit Aethylendiaminsilberphosphat und Arg. nitr. im Verhältniss von 1:4000 vermischten Aufschwemmungen werden nach 5, 10 und 15 llinuten 3 Oesen in gleicher Weise wie oben auf weisse Mäuse übertragen. Sämmtliche Thiere blieben gesund. Es hatten demnach die Mikroorganismen bereits nach 5 Minuten ihre Virulenz verloren.

\section{Desinfectionsprüfung gegenüber Milzbrand-Bacillen und Sporen.}

Um eine Aufschwemmung von Milzbrandbacillen zu gewinnen, wurde nach Geppert's Vorgange folgendermassen verfahren. Lungen, Leber und Milz einer an Milzbrand gestorbenen weissen Maus werden mit steriler Scheere in kleine Stücke geschnitten, in sterilem Wasser aufgeschwemmt und durch ein Glaswollenfilter gegossen. Das Filtrat war eine schwach getrübte, röthliche Flüssigkeit, welche wesentlich vereinzelte, rothe Blutkörperchen, spärliche Leukocyten und äusserst zahlreiche Milzbrandbacillen enthielt. In Rengensgläschen mit je 3 cem dieser Aufschwemmung wurden gleiche Mengen Arg. nitr. 1:2000, Aethylendiaminsilberphosphat 1:2000 und steriles Wasser gebracht. Während nun die mit Silberphosphat versetzte, trübe Aufschwemmung klar und durchsichtig wurde, entstand beim Zusatz von Arg. nitr. ein wolkiger Niederschlag, der sich nach kurzer Zeit zu Boden senkte und etwa $1 / 10$ des Flüssigkeitsvolumens einnahm. ${ }^{1}$

\footnotetext{
1 Auch beim Zusatz einer 2 procentigen alkalischen Silberlösung wurde die Aufschwemmung klar, während die gleiche Menge einer 2 procentigen Höllensteinlösung einen dicken Niederschlag verursachte.
} 


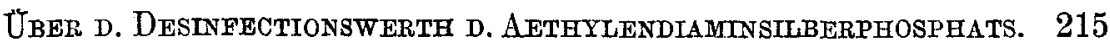

Das Ergebniss des Desinfectionsversuches war, dass bereits die nach 2 Minuten übertragenen Keime sich nicht entwickelten, während die Controlgläschen reichliche Reinculturen von Milzbrand aufwiesen.

Zu den Versuchen mit Milzbrandsporen wurden Aufschwemmungen von Agarculturen verwandt, welche noch 5 Tage nach Beginn der ersten Sporenbildung bei $37.5^{\circ} \mathrm{C}$. aufbewahrt wurden, da man nach Behring's Angabe gerade auf diese Weise sehr zahlreiche Sporen von grosser und gleicher Widerstandsfähigkeit erhält. Bekanntlich weisen die Milzbrandsporen von verschiedener Herkunft sehr erhebliche Differenzen ihrer Resistenzfähigkeit auf; v. Esmarch hat in seiner bereits erwähnten Schrift "Die Milzbrandsporen als Testobject bei Prüfung von 'Desinficientien" nachgewiesen, dass die Unterschiede der Widerstandsfähigkeit verschiedener Milzbrandeulturen ungemein grosse sind, dass eine Anzahl Sporen in 5 procentiger Carbolsäure schon am vierten Tage vollkommen getödtet war, während andere noch nach einem Monat und länger wachsthumsfähig blieben. Die auf die oben angegebene Weise gewonnenen, zu unseren Versuchen verwandten Milzbrandsporen waren, wie mikroskopisch constatirt wurde, ungemein reichlich und von sehr grosser Widerstandsfähigkeit, da sie in einer Aufsehwemmung von verdünntem Blutserum durch 5 Procent Carbollösung in 7 Wochen keineswegs vernichtet und in ihrer Entwickelungsfähigkeit nur ganz unmerklich beeinflusst waren.

Die mit diesen Sporen angestellten Versuche ergaben nun ganz im Gegensatz zu den bisher erbaltenen Resultaten, dass die Desinfectionskraft des Aethylendiaminsilberphosphats derjenigen einer gleichprocentigen Argentum nitricum-Lösung nachstand. Es wird nun allerdings gewöhnlich das Verhalten eines Desinfectionsmittels gegenüber den resistenten Milzbrandsporen als Maassstab der Leistungsfähigkeit betrachtet, thatsächlich aber kommt bei der praktischen Verwendung des hier geprüften Silberphosphats die Vernichtung von Sporen gar nicht in Betracht.

Die in der beschriebenen Weise hergestellte Aufschwemmung der Milzbrandsporen war eine leicht getrübte Flüssigkeit,- in welcher beim Zusatz der gleichen Menge 0.05 Procent Arg. nitr. sich ein feinflockiger Niederschlag bildete, während beim Versetzen mit dem Aethylendiaminsilbersalz die Trübung sogar geringer wurde. Der Desinfectionsversuch, welcher nach der gewöhnlichen Art vorgenommen wurde, wurde 3 Stunden lang fortgesetzt; es war selbst nach dieser Zeit überall noch reichliches Wachsthum zu constatiren. Bei Einwirkung einer $1 / 4$ procentigen Silberlösung ergab sich folgendes Resultat; 
Aufschwemmung von Milzbrandbacillen mit reichlicher Sporenbildung in Wasser.

\begin{tabular}{|c|c|c|c|c|c|}
\hline Uebertragung nach: & 5 Min. & 10 Min. & $20 \mathrm{Min}$. & 30 Min. & $45 \mathrm{Min}$. \\
\hline $\begin{array}{c}\text { Argentum nitricum } 1 / 4 \% \\
\text { Aethylendiamin- } \\
\text { Silberphosphat } 1 / 4 \%\end{array}$ & $\begin{array}{l}\text { reichlich } \\
\text { reichlich }\end{array}$ & $\begin{array}{c}\text { spärlich } \\
\text { desgl. }\end{array}$ & $\begin{array}{c}\text { desgl. } \\
\text { spärlich }\end{array}$ & $\begin{array}{l}\text { desgl. } \\
\text { desgl. }\end{array}$ & $\begin{array}{c}0 \\
\text { desgl. }\end{array}$ \\
\hline Uebertragung nach: & 1 Std. & $11 / 4$ Std. & $11 / 2$ Std. & 2 std. & \\
\hline $\begin{array}{c}\text { Argentum nitricum } 1 / 4 \% \\
\text { Aethylendiamin- } \\
\text { Silberphosphat } 1 / 4 \%\end{array}$ & \begin{tabular}{|c|}
0 \\
vereinzelte \\
Colonieen
\end{tabular} & $\begin{array}{l}0 \\
0\end{array}$ & $\begin{array}{l}0 \\
0\end{array}$ & $\begin{array}{l}0 \\
0\end{array}$ & \\
\hline
\end{tabular}

Aufschwemmung von Milzbrandbacillen mit reichlicher Sporenbildung in Nährbouillon.

\begin{tabular}{c|c|c|c|c|c}
\hline Uebertragung nach: & 5 Min. & 10 Min. & 20 Min. & 30 Min. & 45 Min. \\
\hline Argentum nitricum $1 / 4 \%$ & reichlich & desgl. & desgl. & spärlich & desgl. \\
Aethylendiamin- & reichlich & desgl. & desgl. & desgl. & spärlich \\
Silberphosphat $1 / 4 \%$ & & & & &
\end{tabular}

\begin{tabular}{|c|c|c|c|c|}
\hline Uebertragung nach: & 1 Std. & $11 / 4$ Std. & 11/. Std. & 2 Std. \\
\hline Argentum nitricam $1 / 4 \%$ & $\begin{array}{l}\text { vereinzelte } \\
\text { Colonieen }\end{array}$ & 0 & 0 & 0 \\
\hline $\begin{array}{l}\text { Aethylendiamin- } \\
\text { Silberphosphat } 1 / 4 \%\end{array}$ & desgl. & $\begin{array}{l}\text { sehr spärl. } \\
\text { einz. Col. }\end{array}$ & 0 & 0 \\
\hline
\end{tabular}

Ein gleicher Versuch mit einer 1 procentigen Arg. nitr.- und Aethylendiaminsilberlösung zeigte, dass die Sporen in wässriger Aufschwemmung von ersterer Lösung bereits in 5 Minuten, von letzterer in 15 Minuten vernichtet wurden. Es war demnach in allen drei Versuchen die $A b-$ tödtung der Sporen durch Arg. nitr. einige Minuten früher eingetreten.

Ebenso wie bei den Versuchen mit Micrococcus tetragenus wurde auch hier das Thierexperiment zur Prüfung der Virulenz der Milzbrandsporen nach verschieden langer Einwirkung des Desinficiens verwandt.

Die Versuchsanordnung entsprach der oben geschilderten. Die Milzbrandsporenaufschwemmung wurde in gleicher Weise wie beim vorigen Versuch hergestellt. Zur Controle wurden aus der mit gleichen Theilen sterilen Wassers vermischten Aufschwemmung drei Platinösen in eine Hauttasche zweier weissęn Mäuse hineingebracht, desgleichen drei Oesen auf Agar und Bouillon 
übertragen. Die Controlthiere starben nach 21 bezw. 23 Stunden; in dell untersuchten Organen fanden sich äusserst reichlich Milabrandbaeillen. Der Sectionsbefund war charakteristisch. Die entsprechenden Controlculturen waren sämmtlich gewachsen. Zwei Reagensgläschen mit je $3^{\mathrm{cem}}$ der Aufschwemmung wurden nun mit der gleichen Menge 1/2 procentiger Arg. nitr.bezw. Silberphosphatlösung versetzt, wobei das bereits erwähnte verschiedene Verhalten der Flüssigkeit wieder sehr deutlich war. Aus den beiden Aufschwemmungen wurden nun im Zwischenraum von 10 Minuten drei Platinösen auf Agar und Bouillon übertragen nnd nach 70, 90 und 120 Minuten je eine weisse Maus geimpft. Die Resultate, welche mittels des Culturverfahrens gewonnen wurden, entsprachen den in der Tabelle verzeichneten; die dem Arg. nitr. ausgesetzten Sporen waren nicht mehr entwickelungsfähig nach 50 Minuten, die dem Silberphosphat exponirten nach 70 Minuten.

Das Thierexperiment dagegen gab eine Bestätigung der von Geppert constatirten Thatsache, dass die Thiere noch an Milzbrand sterben zu einer Zeit, wo die entsprechende Cultur nicht mehr angeht. Während die nach 50 bezw. 70 Minuten übertragenen Sporen - wenigstens bei der von mir angewandten Prüfungsmethode - sich als abgetödtet erwiesen, waren dieselben in beiden Fällen nach 90 Minuten noch infectiös.

Die Resultate waren folgende:

Impfung mit drei Oesen der Aufschwemmung, die 70 Minuten der $1 / 1$ procentigen Argent. nitric.-Lösung exponirt war. Die Maus stirbt nach etwa sechs Tagen. Typischer Sectionsbefund: in der Lunge, Milz, im Herzblut viele Milzbrandbacillen.

Impfung mit drei Oesen der Aufschwemmung, die 70 Minuten der $1 / \mathrm{f}$ procentigen Aethylendiaminsilberphosphatlösung exponirt war. Die Maus stirbt schon nach 50 Stunden an Milzbrand. Charakteristischer Sections. befund. In den Organen und im Blut zahlreiche Bacillen.

Impfung aus der Aufschwemmung mit Arg. nitr. (1/4 Procent) nach 90 Minuten. Die Maus stirbt nach etwa fünf Tagen an Milzbrand (Bacillen im Blut u. s. w.).

Impfung aus der Aufschwemmung mit Aethylendiaminsilberphosphat $(1 / 1$ Procent) nach 90 Minuten. Das Versuchsthier geht nach 46 Stunden an Milzbrand zu Grunde.

Die aus den beiden Milzbrandemulsionen nach 120 Minuten geimpften Mäuse blieben beide gesund.

Die Thatsache, dass die Versuchsthiere, welche aus der mit Arg. nitr. versetzten Milzbrandaufschwemmung geimpft wurden, viel später starben als diejenigen Thiere, welche aus der mit Silberphosphat gemischten Sporenemulsion inficirt wurden, erklärt sich wohl dadurch, dass die Arg. nitr.Lösung in der gleichen Zeit mehr Keime getödtet hatte, als das Aethylendiaminpräparat. Es ist demnach im ersteren Falle eine geringere Menge von Sporen auf das Thier übertragen worden, weshalb dasselbe der Milzbrandinfection langsamer erlag. 
Ich komme nun zur Prüfung der Desinfectionskraft des neuen Mittels gegenüber dem Micrococcus gonorrhoeae Neisser, eine Frage, deren Entscheidung um so wichtiger ist, als das Aethylendiaminsilberphosphat seine praktische Verwendung besonders als Antigonorrhoicum finden soll.

Desinfectionsversuche sind meines Wissens mit Gonokokken noch nicht gemacht worden. Bumm (12) hat zwar dem als Culturboden dienenden menschlichen Serum vorher Lösungen der gebräuchlichsten Antiseptica zugesetzt und gefunden, dass schon minimale Verdünnungen das Wachsthum der Gonokokken vollständig hemmten; er hat also hierbei nicht die Desinfectionskraft, sondern vielmehr die Entwickelungshemmung der betreffenden Mittel gegenüber den Gonokokken geprüft. Die Versuche, welche Kreis (13) über den Einfluss der Antiseptica auf die aus gonorrhoischem Eiter gezüchteten Kokken anstellte, sind nicht als massgebend zu erachten, da die Echtheit der von demselben verwandten Culturen später bestritten wurde. Auch an der Gonokokkennatur der von Latteux (14) zu seinen Ichthyolversuchen benutzten Mikroorganismen darf man wohl berechtigten Zweifel hegen, da dieselben auf Glycerinagar gezüchtet wurden, was ja bei echten Gonokokken nicht möglich ist.

Die von mir zur Desinfectionsprüfung verwandten Gonokokken wurden nach der von Wertheim (15) angegebenen Methode aus einer männlichen, seit fünf Tagen an Gonorrhoe erkrankten Harnröhre gewonnen. Die auf Serumagar reichlich gewachsenen Reinculturen stellten thautropfenähnliche, fast farblose Colonieen dar und confluirten nach zwei bis drei Tagen zu einem durchsichtigen Rasen mit leicht welliger Begrenzung. Auf Agar übertragen zeigten sie niemals Entwickelung. Eine Probe dieser Culturen auf dem Objectträger verstrichen und mit Methylenblan gefärbt liess deutliche Diplokokken von etwas verschiedener Grösse erkennen; nach der Gram'schen Methode wurden sie entfärbt. Die genannten Eigenschaften waren nach der von Steinschneider in seiner Arbeit über die Culturen der Gonokokken (16) ausgesprochenen Ansicht ausreichend um die Culturen als Reinculturen von Gonokokken zu charakterisiren. Ich habe anfänglich versucht die Desinfectionsprüfung in der oben beschriebenen Weise mit einer Aufschwemmung in sterilem Wasser vorzunehmen, habe indessen sehr bald hiervon Abstand genommen; es wuchsen nämlich die aus der wässrigen Aufschwemmung überimpften Controlculturen sehr spärlich, nach einiger Zeit (etwa nach fünf Stunden) gar nicht mehr, indem offenbar die sehr empfindlichen Mikroorganismen schon durch den Aufenthalt in sterilem Wasser (von etwa $37.5^{\circ} \mathrm{C}$.) erheblich geschädigt wurden. Es stellte sich bei diesen Versuchen heraus, dass die Gonokokken selbst durch sehr verdünnte Desinfectionslösungen auch nach kürzester 
Einwirkung vollstïndig entwickelungsunfähig geworden waren. Es war also nothwendig, bei der so hochgradigen Empfindlichkeit dieser Mikroorganismen besondere Vorsiehtsmassregeln anzuwenden, um vergleichende Desinfectionsversuche mit denselben vornehmen zu können. Mehrere Versuche führten nun dazu die Aufschwemmung der Gonokokken in verdünntem menschlichen Blutserum herzustellen. Ein Theil des Sèrums, welches vorher $1 / 2$ Stunde lang auf $60^{\circ}$ erhitzt worden war, wird mit zwei Theilen sterilen Wassers gemischt, und in die auf 35 bis $37^{\circ} \mathrm{C}$. erwärmte Flüssigkeit werden zwei Tage alte, auf Serumagar gezüchtete Gonokokken übertragen, so dass zu etwa $2^{\mathrm{ccm}}$ der Aufschwemmung die Culturen eines Serumagarröhrchens verwandt wurden. Die Suspension wurde so lange geschüttelt, bis die mikroskopische Untersuchung eine genügende Vertheilung der Diplokokken erkennen liess; filtrirt wurde nicht. Aus dieser Aufschwemmung mit gleichen Theilen Wasser wuchsen die Controlculturen sehr reichlich, selbst wenn die Ueberimpfung nach vielen Stunden stattfand.

Im Uebrigen wurde in der gewöhnlichen Weise verfahren; es wurde das Desinficiens in der gewünschten Verdünnung zugesetzt, und nach verschiedenen Zeiträumen die Uebertragung von 3 Platinösen auf Serumagar vorgenommen. In dieser Weise werden nicht nur die beiden Silberlōsungen, sondern auch mehrere der als Antigonorrhoica verwandten Flüssigkeiten in der üblichen Verdünnung untersucht.

Die Prüfung der in der nachfolgenden Tabelle angegebenen Desinfectionsmittel konnte nicht an einem einzigen Tage und somit auch nicht an ein und derselben Gonokokkenaufschwemmung vorgenommen werden; indessen wurde dieselbe jedesmal möglichst gleich hergestellt.

Sehr verschieden war die Veränderung. welche der Zusatz des einzelnen Desinfectionsmittels in dem gonokokkenhaltigen Serum hervorrief; die Silberlösungen in einer Concentration 1:2000 verursachten nur einc leichte Trübung, das Ammonium sulfo-ichthyolicum machte nur eine Braunfärbung, ohne einen Niedersehlag zu bilden; dagegen entstand beim Zusatz der schwachen Rotter'schen Lösung ein starker Niederschlag, der etwa $1 / 3$ des Flüssigkeitsvolumens einnahm; 2 procentiges Alumnol verursachte eine noch bedeutendere Fällung ron weissen, flockigen Massen, die sich nach kurzer Zeit absetzten und fast ${ }^{3} / 4$ Theile des Inhaltes betrugen. Beim Versetzen mit 1 procentiger Zinklösung entstand ein so massiger Niederschlag, dass beim Ueberimpfen aus diesem Gemisch sehr erhebliche Mengen der ausgefallten Substanzen übertragen wurden, welche das Wachsthum der Gonokokken auf dem neuen Nährboden vollständig verhinderten. Die soeben geschilderten Verhältnisse scheinen mir deshalb ein besonderes Interesse zu haben, weil es auch bei der praktischen Ver- 
wendung der einzelnen Medicamente als Antigonorrhoica von grosser Wichtigkeit ist, in welchem Maasse dieselben mit eiweiss- und kochsalzhaltigen Flüssigkeiten unlösliche Verbindungen bilden.

Das Ergebniss der Desinfectionsversuche war folgendes:

Aufschwemmung von Gonokokken in verdünntem menschlichen Blutserum von $37^{\circ} \mathrm{C}$.

\begin{tabular}{|c|c|c|c|c|c|c|c|}
\hline Expositionsdauer: & 2 Min. & 5 Min. & $7 \% / 2 \mathrm{Min}$. & 10 Min. & 15 Min. & 20 Min. & 25 Min. \\
\hline n nitr. $1 / 4000$ & s. reichl. & reíchl. & spärl. & 0 & 0 & 0 & \\
\hline $\begin{array}{l}\text { Aethylendiamin- } \\
\text { Silberphosphat }{ }^{1}{ }_{4000}\end{array}$ & $\begin{array}{c}\text { zahlr. } \\
\text { einz.Col. }\end{array}$ & s. spärl. & 0 & 0 & 0 & 0 & \\
\hline Sublimat $1 / 10000$ & reichl. & desgl. & spärl. & desgl. & 0 & 0 & 0 \\
\hline um sulfo- & s. reichl. & desgl. & desgl. & reichl. & desgl. & desgl. & spärl. \\
\hline $\begin{array}{l}\text { Ammonium sulfo- } \\
\text { ichthyol. } 2 \%\end{array}$ & reichl. & desgl. & desgl. & desgl. & 0 & 0 & 0 \\
\hline AlumnoI $1 \%$ & reichl. & desgl. & desgl. & desgl. & zahlr. & desgl. & $\begin{array}{l}\text { s. spärl. } \\
\text { einz.Col. }\end{array}$ \\
\hline $\begin{array}{l}\text { Rotter'sche Lösung } \\
\text { (1 Pastille auf } 1 / 4 \text { Lit.) }\end{array}$ & s. reichl. & desgl. & descl. & reichl. & desgl. & desgl. & desgl. \\
\hline
\end{tabular}

Wie aus dieser Tabelle ersichtlich, ist die abtödtende Kraft der Silberlösungen (insbesondereder alkalischen) gegenüber Gonokokken die grösste, wie dies auch die mit denselben erzielten therapeutischen Resultate erwarten liessen. Das Desinfectionsexperiment ist eine Bestätigung der klinisch feststehenden Thatsache, dass bei der Anwendung der Argentumlösungen die Gonokokken am schnellsten aus dem Harnröhrensecret schwinden.

Ich bemerke, dass ich gegenwärtig noch damit beschäftigt bin, die Desinfectionsversuche mit Gonokokken weiter fortzusetzen und die Einwirkung der zahlreichen in der Praxis verwandten Antigonorrboica nicht nur bei verschieden langer Einwirkung, sondern auch bei Aenderung der Concentration zu prüfen. Die hierbei gewonnenen Resultate sollen an anderer Stelle mitgetheilt werden.

Die bisher aufgezählten Versuchsergebnisse lehren nun, dass das Aethylendiaminsilberphosphat eine ausserordentlich hohe keimtödtende Kraft gegenüber den verschiedensten Mikroorganismen besitzt, und dass es insbesondere dem un$\mathrm{zweifelhaft}$ sehr wirksamen Arg. nitric. noch um ein bedeatendes überlegen ist. I

1 Mit einer einzigen Ausnahme, welche indessen aus dem bereits erwähnten Grunde nicht sonderlich in die Wagschale fällt. 
ÜbER D. DESINFECTIONSWERTH D. AETHYLENDIAMTNSILBERPHOSPHATS. 221

Es wäre nun noch die Frage zu entscheiden, wie die höhere Desinfectionskraft des zusammengesetzten Präparates gegenüber der Ḧ̈llensteinlösung zu èrklären ist.

Es könnte sich hierbei um eine Summirung der Wirkung des Silbersalzes und des Aethylendiamins handeln. Das letztere hat nun thatsächliç, wie spätere Versuche darthun werden, bakterienfeindliche Eigenschaften; indessen sind dieselben so gering, dass diese Erklärung durchaus nicht ausreicht.

Grōsseres Gewicht ist dagegen dem Umstande beizumessen, dass das neue Argentumpräparat von alkalischer Reaction ist, und dass hierbei vielfachen Untersuchungen zu Folge die antibakterielle Kraft des Silbers zu höherer Entfaltung gelangt. Besonders aber ist wohl Folgendes zu berücksichtigen. Die antiparasitäre Wirkung eines Desinficiens kommt zu Stande durch eine chemische Verbindung desselben mit dem Zellleib der Mikroorganismen. Da nun, wie oben bewiesen wurde, das Aethylendiamin die Fähigkeit besitzt, dem Silbersalz den Weg in's organisehe Gewebe zu bahnen, so wird es dasselbe auch befïhigen, leichter und energischer in ehemische Action mit der organischen Substanz der Bakterien zu treten und seine Giftwirkung auf das Protoplasma derselben besser zu entfalten. So würde sich dann ungezwungen die erhöhte bakterientödtende Kraft des neuen Mittels gegenüber dem einfachen Silbersalze erklären.

Wie sich dies nun auch immer verhalten mag, jedenfalls fordern die grosse Desinfectionskraft und die so erhebliche Tiefenwirkung des Aethylendiaminsilberphosphats auf das Mittel auch praktisch zu prüfen und seine experimentell bewiesenen Vorzüge in der Therapie besonders bei der Behandlung der Gonorrhoe zu verwerthen.

\section{Prüfung der Desinfectionskraft des Aethylendiaminkresols.}

Die erhebliche Verstärkung der Desinfectionskraft und die Vermehrung der Tiefenwirkung, welche durch den Zusatz des Aethylendiamins zur Argentumverbindung erzielt wurden, legten den Gedanken nahe, auch bei anderen Desinfectionsmitteln durch Vereinigung mit der organischen Base die Leistungsfähigkeit zu erhöhen. So stellte die chemische Fabrik auf Actien (vorm. E. Schering) unter anderem das Aethylendiaminkresol dar. Es wurde gerade das Kresol gewählt, weil zahlreiche neuere Arbeiten die sehr grossen Vorzüge dieses Mittels allen anderen Verbindungen der aromatischen Reihe gegenüber hervorhoben. So stellte C. Fränkel fest, dass es die Kresole sind, welche der roben Carbolsäure die so bedeutende, der reinen Carbolsäure überlegene Desinfectionskraft ver- 
leihen; auch ist die relative Giftigkeit des Kresols nach Hüppe's Untersuchungen (17) nur den vierten Theil so gross wie bei den Phenolen. Das zur Herstellung des Aethylendiaminpräparates verwandte Kresol ist ein Gemisch von Para-Meta- und Ortho-Kresol, welches sich als die geeignetste und wirksamste Combination erwiesen hatte.

Das Aethylendiaminkresol ist eine farblose, wasserklare Flüssigkeit von phenolähnlichem Geruche; nach längerem Stehen an der Luft nimmt sie eine hellgelbe Farbe an, behält indessen - wie besonders nachgewiesen wurde - ibre sonstigen speciell desinficirenden Eigenschaften bei.

Die zu den Versuchen verwandte Lösung enthält ebenso viel Aetlhylendiamin als Kresol; die Reaction derselben ist alkalisch entsprechend dem Gehalte an Aethylendiamin. ${ }^{1}$ Die Löslichkeit des Kresols wird durch Zusatz der organischen Base bedentend erhöht; nach einer Mittheilung der chemischen Fabrik mischen sich Kresol und Athylendiamin im Verhältniss von 1:1.8 mit Wasser in allen Verhältnissen. Ein anderer Vortheil der neuen Lösung besteht darin, dass sie mit eiweisshaltigen Flüssigkeiten und Körpern weniger Gerinnung giebt, als eine entsprechende Lösung ohne den Zusatz des Aethylendiamins.

Was die Giftigkeit des zu prüfenden Präparates anbetrifft, so ist bereits erwähnt worden, dass die Kresolverbindungen überhaupt verhăltnissmässig wenig giftig sind; es war demnach nicht anzunehmen, dass dies bei dem Aethylendiaminkresol der Fall sein würde, da ja die Giftwirkung des Aethylendiamins selbst wach den obigen Versuchen eine sehr geringe war. Zur experimentellen Prüfung wurden Kaninchen Aethylendiaminkresollösungen injicirt; es wurde von $1 \mathrm{~cm}$ einer 2 procentigen bis zu $10^{\mathrm{cem}}$ einer 4 procentigen Lösung gestiegen; abgesehen von einem leichten Infiltrat im letzten Falle blieben die Versuchsthiere völlig gesund. Die Fresslust war unverändert, das Körpergewicht blieb auf derselben Höhe; auch die Blutuntersuchungen liessen keine Veränderung der Blutkörperchen oder des Hämoglobingehaltes constatiren.

Ebenso zeigten sich bei der praktischen Verwendung des Mittels niemals unangenehme Nebenerscheinungen. So wurden z. B. beide Arme eines an hochgradiger Psoriasis leidenden Patienten vier Tage lang mit 2 procentigem Aethylendiamin feucht verbunden. Obgleich bekanntlich die Psoriasishaut ein sehr bedeutendes Resorptionsvermögen besitzt, traten dennoch keinerlei Intoxicationserscheinungen auf.

In ähnlicher Weise wie beim Aethylendiaminsilberphosphat liess sich auch beim Aethylendiaminkresol constatiren, dass dasselbe in erstarrte Gelatine leichter eindrang als eine gewöhnliche Kresollösung. Da jedoch

${ }_{1} 100^{\mathrm{ecm}} 10$ proc. Aethylendiaminlösung entsprechen 333 cem Normalnatronlauge. 
Über D. DesiNFECTIONSWERTH D. AETHYLENDIAMINSIIBERPHOSPHATS. 223

das Vordringen dieser Präparate nicht wie bei den Silberverbindungen durch Lichteinwirkang darstellbar war, wurden die betreffenden Lösungen gefärbt; so zeigte sich, dass $1 / 2$ und 1 procentiges Aethylendiaminkresol viel tiefer in der gleichen Zeit in die Gelatine drangen, als die entsprechenden Kresolpräparate; durch die mit Aethylendiamin vermischten Lösungen war übrigens die Gelatine nach zwei Tagen vollständig aufgelöst.

Schliesslich sei noch erwähnt, dass Metallinstrumente von dem neuen Präparat nicht angegriffen werden, selbst wenn dieselben 24 Stunden in einer 1 procentigen Lösung verbleiben; die Farbe mehrerer bunter Stoffe wurde selbst nach mehrtägigem Verweilen in einer 1 procentigen Lösung nicht verändert, ebenso wenig der Stoff selbst geschädigt. Beim Gebrauch für die Desinfection der Hände hat das Aethylendiaminkresol den Vortheil, dieselben nicht schlüpfrig zu machen wie die seifenhaltigen Präparate; das sonstige Verhalten namentlich mit Bezug auf Erzeugung von Parästhesieen der Fingerspitzen ist ähnlich wie bei der Carbollösung. Endlich ist hervorzuheben, dass die Reiz- und Aetzwirkung selbst in höheren Concentrationen und die Hervorrufung von Eiweissgerinnung viel unbedeutender ist, als bei antiseptisch gleichwerthigen Präparaten aus der aromatischen Reihe.

Die Technik der Desinfectionsversuche war genau die gleiche wie die bei der Prüfung des Silberphosphats, so dass es sich erübrigt, die Versuchsanordnung hier nochmals anzugeben. Gleichzeitig mit dem Aethylendiaminkresol wurde auch eine entsprechende Lösung von Kresol untersucht, einestheils um zu constatiren, wie sehr die Leistungsfähigkeit des Mittels durch Zusatz der organischen Verbindung erhöht wurde, anderntheils um einen Vergleichswerth mit einem bekannten und bereits bewährten Antisepticum zu erhalten. In einzelnen Fällen wurde aus letzterem Grunde auch noch Carbolsäure und Solveol in entsprechender Concentration geprüft; endlich wurde fast stets auch das Aethylendiamin allein auf seine antibakterielle Kraft untersucht, wobei sich die letztere als so unbedeutend erwies, dass die sehr erhöhte Leistungsfähig. keit des Aethylendiaminkresols gegenüber dem Kresol durch eine einfache Summirung der Desinfectionskraft der beiden Verbindungen nicht erklärt werden könnte. Es dürfte wohl auch hier der für die Wirkungsweise der combinirten Silberlösung oben auseinandergesetzte Erklärungsversuch eine gewisse Berechtigung haben. Vor der Mittheilung der Desinfectionsexperimente sollen noch ganz kurz die Versuche erwähnt werden, welche sich mit der entwickelungshemmenden Eigenschaft der in Frage stehenden Körper beschäftigen. Auf Agar, welches Aethylendiaminkresol im Verhältniss 1:1000 enthielt, zeigten sämmtliche überimpften Mikroorganismen deutliche Wachsthumsstörung, dagegen blieb in keinem Falle 
die Entwickelung vollständig aus. Sehr erheblich gegenüber den Controlculturen war der Unterschied bei Bacillus prodigiosus, Micrococcus tetragenus, Diploc. urethrae, Staphyloc. pyog. aureus und Choleraspirillen, weniger ausgesprochen bei Milzbrandbacillen mit Sporen und Bac. pyocyaneus. Wurde dem Nährboden das Antisepticum im Verbältniss von $1 /{ }_{4}$ Procent beigemischt, so blieben sämmtliche Mikroorganismen entwickelungsunfähig mit Ausnahme der sporenhaltigen Milzbrandculturen; von drei hiermit geimpften Reagensgläschen zeigten zwei derselben je eine Colonie.

Die Prüfung der entwickelungshemmenden Kraft des Aethylendiamins allein in gleicher Weise vorgenommen, ergab fast genau dieselben Resultate. Bei einem Zusatz von 0.1 Procent deutliche Wachsthumsbehinderung; bei einem Gehalt von $1 / 4$ Procent Aethylendiamin vollständige Entwickelungshemmung mit Ausnahme von ganz spärlichem Wachsthum der Milzbrandbacillen und des Diplococcus urethrae in einem Agarröhrchen.

Die Desinfectionsprüfung der genannten Präparate wurde im Allgemeinen bei einem Procentgehalt von $1 / 4$ vorgenommen, weil nach mehreren Vorversuchen gerade bei dieser Concentration gut vergleichbare Resultate gewonnen wurden.

Aufschwemmung von Bacillus prodigiosus in sterilem Wasser.

\begin{tabular}{|c|c|c|c|c|c|}
\hline Ueberimpfung nach: & 5 Min. & $10 \mathrm{Min}$. & 20 Min. & 30 Min. & $45 \mathrm{Min}$. \\
\hline $1 / 4$ procentiges Kresol & $\begin{array}{l}\text { sehr } \\
\text { reichlich }\end{array}$ & desg1. & reichlich & $\begin{array}{l}\text { zahlreiche } \\
\text { einz. Col. }\end{array}$ & desgl. \\
\hline $1_{4}$ proc. Aethylendiamin. & reichlich & $\begin{array}{l}\text { zahlreiche } \\
\text { einz. Col. }\end{array}$ & 1 Col. auf & 0 & 0 \\
\hline $1 / 4$ proc. Aethylendiamin & s. reichl. & desgl. & desgl. & reichlich & desgl. \\
\hline
\end{tabular}

\begin{tabular}{c|c|c|c|c|c|c|c}
\hline Ueberimpfung nach: & 1 Std. & $11 / 4$ Std. & $11 /$ Std. & 2 Std. & $21 / 2$ Std. & $2+$ Std. \\
\hline 1/4 procentiges Kresol & z. einz.Col. spärl. Col. & desgl. & 0 & 0 & 0 \\
1/4 proc. Aeth.-diam.-Kresol & 0 & 0 & 0 & 0 & 0 & 0 \\
1/4 proc. Aethylendiamin & reichlich & vereinz.C. & desgil. & desgl. spärl. C. & 0
\end{tabular}

Dieselbe Aufschwemmung.

\begin{tabular}{c||c|c|c|c|c}
\hline Ueberimpfung nach: & 2 Min. & 5 Min. & 10 Min. & 20 Min. & 30 Min. \\
\hline 1/2 procentiges Kresol & reichlich & desgl. & desgl. & z. einz. Col. & desgl. \\
$1 / 2$ proc. Aeth.-diamin-Kresol & 0 & 0 & 0 & 0 & 0 \\
$1 \%$ proc. Aethylendiamin & s. reichl. & desgl. & desgl. & desgl. & desgl.
\end{tabular}


(Fortsetzung.)

\begin{tabular}{|c|c|c|c|c|c|}
\hline Ueberimpfung nach: & $4 \check{M i n}$. & $1 \mathrm{Std}$. & $11 / 4-2$ Std. & 3 Std. & 12 Std. \\
\hline $1 / 2$ procentiges Kresol & $\begin{array}{l}\text { spärliche } \\
\text { einz. Col. }\end{array}$ & 0 & 0 & 0 & 0 \\
\hline $\begin{array}{l}1 / 2 \text { proc. Aeth.-diam.-Kresol } \\
1 / 2 \text { proc. Aethylendiamin }\end{array}$ & $\begin{array}{c}0 \\
\text { reichlich }\end{array}$ & $\begin{array}{c}0 \\
\text { desgl. }\end{array}$ & $\begin{array}{c}0 \\
\text { spärlich }\end{array}$ & $\begin{array}{c}0 \\
\text { desgl. }\end{array}$ & $\begin{array}{l}0 \\
0\end{array}$ \\
\hline
\end{tabular}

Aufschwemmung von Bacillus pyocyaneus in mensehlichem Blutserum.

\begin{tabular}{|c|c|c|c|c|c|}
\hline Ueberimpfung nach: & 2 Min. & 5 Min. & 10 Min. & $20 \mathrm{Min}$. & 30 Min. \\
\hline $1 / 4$ procentiges Kresol & & & $\begin{array}{l}\text { zahlreiche } \\
\text { einz. Col. }\end{array}$ & desgl. & spärl. Col. \\
\hline $\begin{array}{l}1 / 4 \text { proc. Aeth.-diamin-Kresol } \\
1 / \% \text { proc. Aethylendiamin }\end{array}$ & $\begin{array}{l}\text { reichlich } \\
\text { s. reichl. }\end{array}$ & $\begin{array}{l}\text { einz. Col. } \\
\text { desgl. }\end{array}$ & $\begin{array}{c}0 \\
\text { desgl. }\end{array}$ & $\begin{array}{c}0 \\
\text { desgl. }\end{array}$ & $\begin{array}{c}0 \\
\text { desgl. }\end{array}$ \\
\hline Ueberimpfung nach: & 45 Min. & 1 Std. & $1-4$ Std. & 5 Strl. & 10 Std. \\
\hline $1 / 4$ procentiges Kresol & 0 & 0 & 0 & 0 & 0 \\
\hline $\begin{array}{l}1 / 4 \text { proc. Aeth.-diamin-Kresol } \\
1 / 4 \text { proe. Aethylendiamin }\end{array}$ & $\begin{array}{c}0 \\
\text { S. reichl. }\end{array}$ & $\begin{array}{c}0 \\
\text { desgl. }\end{array}$ & $\begin{array}{c}0 \\
\text { desgi. }\end{array}$ & $\begin{array}{c}0 \\
\left.\text { einz. } \mathrm{C}_{0}\right]\end{array}$ & $\begin{array}{c}0 \\
\text { späri. Col. }\end{array}$ \\
\hline
\end{tabular}

Dieselbe Aufschwemmung.

\begin{tabular}{|c|c|c|c|c|c|c|c|}
\hline Ueberimpfong nach: & 2 Min. & 5 Min. & 10 Min. & 20 Min. & 30 Min. & 45 Min. & $1-5$ Std. \\
\hline $1 / 2$ procentiges Kresol & $\begin{array}{c}\text { zahlr. } \\
\text { einz.Col. }\end{array}$ & desgl. & $\begin{array}{l}\text { spärl. } \\
\text { Col. }\end{array}$ & desgl. & 0 & 0 & 0 \\
\hline $\begin{array}{c}1 / 2 \text { proc. Aethylendiam.- } \\
\text { Kresol }\end{array}$ & 0 & 0 & 0 & 0 & 0 & 0 & 0 \\
\hline 1/2 proc. Carbolsäure & s. reichl. & desgl. & desgl. & desgl. & desgl. & reichl. & $\begin{array}{l}\text { allmählich } \\
\text { bis vereinz. } \\
\text { Colonieen } \\
\text { abnehmend }\end{array}$ \\
\hline
\end{tabular}

Bei den letzten beiden Versuchen zeigte sich, um wie riel die A ethylendiaminkresollösung an Desinfectionskraft dem Kresol insbesondere aber der Carbolsäure bei gleicher Concentration überlegen ist; während z. B. von einer $1 / 4$ procentigen Aethylendiaminkresollösung die Pyocyaneusbacillen im Blutserum bereits nach 10 Minuten abgetödtet waren, war dies durch eine gleichprocentige Carbollösung noch nicht nach 10 Stunden vollständig erreicht. Es war gleichzeitig auch ein Versuch mit $1 / 4$ bezw. $1 / 2$ procentiger Solveollösung angestellt worden, wobei sich ergab, dass im ersteren Falle noch nach 10, im zweiten noch nach 5 Stunden reichliches Wachsthum erfolgte; diese Versuchsreihe wurde Zeitschr. A. Hrgiene. XVI. 
jedoch nicht in die Tabellen aufgenommen, da die gleichprocentige Solveollösung einen geringeren Kresolgehalt als die anderen Kresolpräparate haben und sich somit zum directen Vergleich nicht eignen; indessen geht auch aus dem mitgetheilten Versuchsergebniss hervor (ebenso wie aus einem später zu berichtenden Experiment mit Milzbrandsporen), dass die hohe Desinfectionskraft des Aethylendiaminkresols vom Solveol nicht erreicht wird.

Aufschwemmung ron Staphylococcus pyogenes aureus in sterilem Wasser.

\begin{tabular}{|c|c|c|c|c|c|}
\hline Ueberimpfung nach: & $5-30 \mathrm{Min}$ & 45 Min. & 1 Std. & $1 / 2$ Std. & 2 Std. \\
\hline $\begin{array}{c}1 / 4 \text { procentiges Kresol } \\
1 / 4 \text { proc.Aeth.-diamin-Kresol } \\
1 / 4 \text { proc. Aethylendiamin }\end{array}$ & $\begin{array}{l}\text { s. reichl. } \\
\text { reichlich } \\
\text { s. reichl. }\end{array}$ & $\begin{array}{c}\text { reichlich } \\
\text { zahlr. Col. } \\
\text { desgl. }\end{array}$ & $\begin{array}{l}\text { desgl. } \\
\text { desgl. } \\
\text { desgl. }\end{array}$ & $\begin{array}{l}\text { desgl. } \\
\text { desgl. } \\
\text { desgl. }\end{array}$ & $\begin{array}{l}\text { desgl. } \\
\text { spärl. Col. } \\
\text { desgl. }\end{array}$ \\
\hline Ueberimpfung nach: & 3 Std. & 5 Std. & 18 Std. & 24 Std. & 48 Std. \\
\hline $\begin{array}{c}\text { 1/4 procentiges Kresol } \\
1 / 4 \text { proc.Aeth.-diamin-Kresol } \\
1 / 4 \text { proc. Aethylendiamin }\end{array}$ & $\begin{array}{l}\text { reichlich } \\
\text { spärl. Col. } \\
\text { s. reichl. }\end{array}$ & $\begin{array}{c}\text { desgl. } \\
0 \\
\text { reichlich }\end{array}$ & $\begin{array}{c}\text { zahlr. Col. } \\
0 \\
\text { desgl. }\end{array}$ & $\begin{array}{l}\text { spärl. Col. } \\
0 \\
\text { zahlr. Col. }\end{array}$ & $\begin{array}{l}\text { desgl. } \\
0 \\
\text { desgl. }\end{array}$ \\
\hline
\end{tabular}

Bei einem Desinfectionsversuch mit einer reichlichen Aufschwemmung von Choleraspirillen waren dieselben sowohl durch das Aethylendiamin als auch durch die Kresolpräparate in 1/4 procentiger Lösung schon nach zwei Minuten abgetödtet. Die Controlculturen zeigten reichliches Wachsthum.

Mit Diphtheriebacillen, welche zwei Tage lang auf schräg erstarrtem Agar gewachsen waren, ergaben sich folgende Resultate.

Aufschwemmung von Diphtheriebacillen in sterilem Wasser.

\begin{tabular}{c|c|c|c|c|c}
\hline Ueberimpfung nach: & 5 Min. & 10 Min. & 20 Min. & 30 Min. & 45 Min. \\
\hline \hline $\begin{array}{c}\text { 1/4 procentiges Kresol } \\
\text { 1/4 proc. Aeth.-diamin-Kresol }\end{array}$ & $\begin{array}{c}\text { reichlich } \\
\text { reichlich }\end{array}$ & $\begin{array}{c}\text { desgl. } \\
\text { zahlreiche } \\
\text { einz. Col. } \\
\text { desgl. }\end{array}$ & $\begin{array}{c}\text { desgl. } \\
\text { desgl. } \\
\text { desgl. }\end{array}$ & $\begin{array}{c}\text { desgl. } \\
\text { spärlich } \\
\text { desgl. }\end{array}$ & $\begin{array}{c}\text { spärl. Col. } \\
\text { desgl. } \\
\text { reichlich }\end{array}$ \\
\hline Ueberimpfung nach: & 1 Std. & $11 / 4$ Std. & $11 / 2$ Std. & 2 Std. & 3 Std. \\
\hline \hline 1/4 procentiges Kresol & spärl. Col. & desgl. & 0 & 0 & 0 \\
1/4 proc. Aeth.-diamin-Kresol & spärlich & 0 & 0 & 0 & 0 \\
1/4 proc. Aethylendiamin & reichlich & desgl. & desgl. & desgl. & desgl.
\end{tabular}


ÜBER D. DESINFECTIONSWERTH D. AETHYLENDIAMINSILBERPHOSPHATS. 227

Aufschwemmung ron Diplococeus urethrae in Wasser.

\begin{tabular}{|c|c|c|c|c|c|}
\hline Ueberimpfung nach: & 5 Min. & 10-30Min. & 45 Min. & 1 Std. & $1 / 4$ Std. \\
\hline $\begin{array}{c}\text { 1/4 procentiges Kresol } \\
1 / 4 \text { proc.Aeth.-diamin-Kresol } \\
1 / 4 \text { proc. Aethylendiamin }\end{array}$ & $\begin{array}{l}\text { s. reichl. } \\
\text { s. reichl. } \\
\text { s. reichl. }\end{array}$ & $\begin{array}{l}\text { desgl. } \\
\text { reichlich } \\
\text { desgl. }\end{array}$ & $\begin{array}{l}\text { desgl. } \\
\text { zahlreiche } \\
\text { einz. Col. } \\
\text { desgl. }\end{array}$ & $\begin{array}{l}\text { desgl. } \\
\text { vereinz. } \\
\text { Col. } \\
\text { desgl. }\end{array}$ & $\begin{array}{l}\text { desgl. } \\
\text { s spärl. }{ }^{1} \\
\text { desgl. }\end{array}$ \\
\hline Ueberimpfung nach: & $11 / 2$ Std. & 2 Std. & $21 / 2$ Std. & 18 Std. & 24 Std. \\
\hline $1 / 4$ procentiges Kresol & s. reichl. & desgl. & reichlich & einz. Col. & spärl. Col. \\
\hline $1 / 4$ proc.Aeth.-diamin-Kresol & 0 & 0 & 0 & 0 & 0 \\
\hline $1 / 4$ proc. Aethylendiamin & einz. Col. & desgl. & 0 & 0 & 0 \\
\hline
\end{tabular}

Wiederum war eine erheblich stärkere Desinfectionskraft des Aethylendiaminkresols vorhanden; ebenso auffallend war der Untersehied in der Wirksamkeit gegenüber Typhusbacillen sowohl in sterilem Wasser als in menschlichem Blutserum.

Aufschwemmung von Typhusbacillen in sterilem Wasser.

\begin{tabular}{c||c|c|c|c|c}
\hline Ueberimpfung nach: & 2 Min. & 5 Min. & 10 MIin. & 20 Min. & 30 Min. \\
\hline 1/4 procentiges Kresol & s. reichl. & desgl. & desgl. & desgl. & desgl. \\
1/4 proc.Aeth.-diamin-Kresol & zahl. Col. & desgl. & 0 & 0 & 0 \\
$1 / 4$ proc. Aethylendiamin & s. reichl. & desgl. & desgl. & desgl. & desgl.
\end{tabular}

\begin{tabular}{c||c|c|c|c|c}
\hline \hline Ueberimpfung nach: & $45 \mathrm{Min}$. & 1 Std. & $11 / 4-2$ Std. & $21 / 2$ Stz. & 16 Std. \\
\hline \hline $\begin{array}{c}1 / 4 \text { procentiges Kresol } \\
\begin{array}{c}1 / 4 \text { proc. Aeth.-diamin-Kresol } \\
\text { 1/4 proc. Aethylendiamin }\end{array}\end{array}$ & $\begin{array}{c}\text { s. reichl. } \\
\text { s. reichl. }\end{array}$ & reichlich & $\begin{array}{c}\text { zahlreiche } \\
\text { einz. Col. }\end{array}$ & einz. Col. & 0 \\
0 & 0 & 0 \\
desgl. & zahlr. Col. & desgl. & spärl. Col.
\end{tabular}

Die Aufschwemmung in sterilem menschlichem Blutserum wurde in der gewöhnlichen Weise hergestellt, nachdem das Serum vorher wie oben erwärmt worden war. Die Abtödtung erfolgte später als in sterilem Wasser, indessen war wiederum die Ueberlegenheit des Aethylendiaminkresols sehr deutlich vorhanden. Die Controlculturen zeigten Wachsthum, auch nachdem nach 16 Standen die Uebertragung vorgenommen worden war.

${ }^{1}$ Auf einem Agargläschen 3 Colonieen nach 4 Tagen; das andere blieb steril. 
Aufschwemmung von Typhusbacillen in Serum.

\begin{tabular}{|c|c|c|c|c|c|c|c|c|}
\hline Ueberimpfung nach: & 5 Min. & 10 Min. & 20Min. & 30Min. & $45 \mathrm{Min}$. & $60 \mathrm{Min}$. & $11 / 4^{-2} 2_{2}^{1} \mathrm{St}$. & 16 Std. \\
\hline $1 / 4$ procent. Kresol & $\begin{array}{c}\text { sehr } \\
\text { reichl. }\end{array}$ & desgl. & desgl. & desgl. & desgl. & desgl. & reichlich & $\begin{array}{l}\text { zahlr. } \\
\text { einz. }\end{array}$ \\
\hline $\begin{array}{c}\text { 1/4 proc.Aeth. diamin- } \\
\text { Kresol }\end{array}$ & $\begin{array}{c}\text { sehr } \\
\text { reichl. }\end{array}$ & $\begin{array}{l}\text { reichl. } \\
\text { einz. C. }\end{array}$ & desgl. & desgl. & 0 & 0 & 0 & 0 \\
\hline $\begin{array}{l}1 / 4 \text { proc. Aethylen- } \\
\text { diamin }\end{array}$ & $\begin{array}{c}\text { sehr } \\
\text { reichl. }\end{array}$ & desgl. & desgl. & desgl. & desgl. & desgl. & reichlich & einz. C. \\
\hline
\end{tabular}

Aufschwemmung ron Micrococeus tetragenus in Wasser.

\begin{tabular}{|c|c|c|c|c|c|c|c|c|}
\hline Ueberimpfung nach: & $5 \mathrm{Min}$. & $10 \mathrm{Min}$. & $20 \mathrm{Min}$. & $30 \mathrm{Min}$ & 45 Min. & 1 Std. & $11 / 4 \mathrm{St}$ & $11_{2}^{1 / 2} \mathrm{St}$ \\
\hline $1 / 4$ procent. Kresol & $\begin{array}{c}\text { sehr } \\
\text { reichl. }\end{array}$ & reichl. & desgl. & $\begin{array}{c}\text { einzelne } \\
\text { Col. }\end{array}$ & desgl. & desgl. & desgl. & $\begin{array}{l}\text { spärl. } \\
\text { Col. }\end{array}$ \\
\hline $\begin{array}{l}1 / 4 \text { proc.Aeth.-diamin } \\
\text { Kresol }\end{array}$ & $\begin{array}{l}\text { sehr } \\
\text { reichl. }\end{array}$ & $\begin{array}{l}\text { zahlr. } \\
\text { einz. C. }\end{array}$ & $\begin{array}{l}\text { spärl. } \\
\text { Col. }\end{array}$ & $\begin{array}{c}\text { sehr } \\
\text { spärl. C. }\end{array}$ & $\begin{array}{c}\text { auf } 1 \text { Glas } \\
1 \text { Col. }\end{array}$ & 0 & 0 & 0 \\
\hline$\underset{\text { diamin }}{1 / 4 \text { proc. Aethylen- }}$ & $\begin{array}{c}\text { sehr } \\
\text { reichl. }\end{array}$ & reichl. & desgl. & desgl. & desgl. & desgl. & spärl. & desgl. \\
\hline
\end{tabular}

Die Desinfectionskraft der zu prüfenden Mittel gegenüber Milzbrandsporen wurde bestimmt in einer Aufschwemmung von sterilem Wasser, von Hydrocelenflüssigkeit und Blutserum. Die Abtödtung erfolgte in den beiden letztgenannten Medien später, stets jedoch bei dethylendiaminkresol eher, als bei der einfachen Kresollösung. Aus der grossen Zahl der nach verschiedener Zeit vorgenommenen Ueberimpfungen sollen nur einzelne in den folgenden Tabellen aufgeführt werden.

Aufschwemmung von Milzbrandbacillen mit Sporen in Wasser.

\begin{tabular}{|c|c|c|c|c|c|c|c|}
\hline Ueberimpfung nach: & 1 Std. & 24 Std. & $1 \frac{1}{2} \mathrm{Tgn}$. & 2 Tgn. & 3 Tgn. & $4 \mathrm{Tgn}$. & 5-10 Tgn. \\
\hline 2 procentiges Kresol & s. reichl. & desgl. & reichl. & einz. C. & desgl. & 0 & 0 \\
\hline $\begin{array}{l}2 \text { pros. Aeth-diamin- } \\
\text { Kresol }\end{array}$ & s. reichl. & desgl. & reichl. & 0 & 0 & 0 & 0 \\
\hline
\end{tabular}

Eine 4 procentige Aethylendiaminlösung hatte nach 10 Tagen die Sporen noch nicht vollständig vernichtet, da einzelne derselben noch zur Entwickelung gelangten.

Aufschwemmung von Milzbrandbacillen mit Sporen in Hydrocelenflüssigkeit.

\begin{tabular}{|c|c|c|c|c|c|}
\hline Ueberimpfung nach: & 1 Tag & 3 Tagen & 5 Tagen & 7 Tagen & 9 Tagen \\
\hline $\begin{array}{c}\text { 2procentiges Kresol } \\
\text { 2proc. Aeth.-diamin-Kresol }\end{array}$ & $\begin{array}{l}\text { s. reichl. } \\
\text { s. reichl. }\end{array}$ & $\begin{array}{l}\text { desgl. } \\
\text { reichlich }\end{array}$ & $\begin{array}{l}\text { reichlich } \\
\text { zahlreiche } \\
\text { einz. Col. }\end{array}$ & $\begin{array}{l}\text { desgl. } \\
\text { desgl. }\end{array}$ & $\begin{array}{l}\text { desgl. } \\
3 \text { Col. }\end{array}$ \\
\hline
\end{tabular}




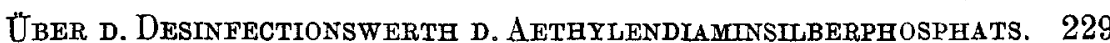

(Fortsetzung.)

\begin{tabular}{c||c|c|c|c|c}
\hline Ueberimpfung nach: & 11 Tagen & 12 Tagen & 14 Tagen & 16 Tagen & $17-21$ Tgn. \\
\hline 2 procentiges Kresol & reichlich & $\begin{array}{c}\text { zahlreiche } \\
\text { einz. Col. }\end{array}$ & spärl. Col. & desgl. & 0 \\
2proc. Aeth.-diamin-Kresol & 0 & 0 & 0 & 0 & 0
\end{tabular}

Der Desinfectionsversuch mit einer Aufschwemmung in Blutserum wurde mit einer 5 procentigen Carbollösung und einer Kresol-, Aethylendiaminkresol- und Solveollösung vorgenommen, deren Gehalt an Kresol 5 Procent betrug. In der Aethylendiaminkresollösung, besonders aber in der Kresollösung war ein Theil des Kresols ungelöst geblieben. Beim Zusatz der Carbolsäure und des Kresols entstand ein starker Niederseblag, in geringerem Maasse beim Versetzen mit Solveol; bei Hinzufügung des Aethylendiaminkresols trat nur eine stärkere Trübung des Serums ein.

Aufschwemmung von Milzbrandbacillen und Sporen in menschlichem Blutserum.

\begin{tabular}{|c|c|c|c|c|c|c|}
\hline \multicolumn{2}{|c|}{ Ueberimpfung nach: } & $1 \mathrm{Tag}$ & 3 Tagen & 5 Tagen & 7 Tagen & 14 Tagen \\
\hline \multicolumn{2}{|c|}{5 procentige Carbolsäure } & s. reichl. & & desgl. & desgl. & desgl. \\
\hline Kresollösung & 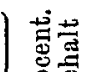 & s. reichl. & reichlich & desgl. & desgl. & $\begin{array}{l}\text { zahlreiche } \\
\text { einz. Col. }\end{array}$ \\
\hline $\begin{array}{l}\text { Aethylendiamin- } \\
\text { Kresollösung }\end{array}$ & 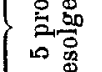 & s. reichl. & reichlich & einz. Col. & desgl. & spärlich \\
\hline Solveollösung & 薢 & s. reichl. & desgl. & desgl. & desgl. & reichlich \\
\hline \multicolumn{2}{|c|}{ Ueberimpfung nach: } & 21 Tagen & 28 Tagen & 35 Tagen & 42 Tagen & 49 Tagen \\
\hline \multicolumn{2}{|c|}{5 procentige Carbolsäure } & s. reichl. & reichlich & desgl. & desgl. & einz. Col. \\
\hline Kresollösung & | & $\begin{array}{l}\text { zahlreiche } \\
\text { einz. Col. }\end{array}$ & spärlich & desgl. & desgl. & $\begin{array}{l}\text { s. spärl. } \\
\text { Colonieen }\end{array}$ \\
\hline $\begin{array}{l}\text { Aethylendiamin- } \\
\text { Kresollösung }\end{array}$ & 政密 & spärlich & 3-5 Col. & 3 Col. & 0 & 0 \\
\hline Solveollösung & 高氙 & reichlich & z. einz. C. & desgl. & desgl. & spärl. Col. \\
\hline
\end{tabular}

Aus der Betrachtung der letzten drei Tabellen geht wiederum deutlich hervor, wie viel auf das Medium ankommt, in welchem die Mikroorganismen abzutödten sind, und dass namentlich im Blutserum dies viel schwieriger ist, als in anderen Flüssigkeiten, worauf bereits von mancher Seite hingewiesen worden ist; ferner ist aus den Versuchen ersichtlich, dass die Resistenz der benutzten Milzbrandsporen eine sehr hohe war, da dieselben in Blutserum aufgeschwemmt durch 7 wöchentliche Einwirkung einer 5 procentigen Carbollösung noch nicht getödtet waren. 
Es wurde schliesslich noch ein Desinfectionsversuch mit Cystitisharn vorgenommen. Der Crin reagirte alkalisch, war sehr trüb und von penetrant fauligem Geruch. Mikroskopisch waren nachzuweisen zahlreiche Eiterkörperchen und eine ungemein grosse Menge von Stäbchen und Kolken. Drei Oesen auf schräg erstarrtem Agar verstrichen zeigten bei $37.5^{\circ} \mathrm{C}$. nach 12 Stunden einen dichten Rasen verschiedenartiger Culturen. In vier Reagensröhrchen werden je 3 cem des Harns eingefüllt, und zu jedem die betreffenden Desinficientien in $1 / 2$ procentiger Lösnng zugesetzt.

Desinfectionsversuch mit Cystitisharn.

\begin{tabular}{|c|c|c|c|c|c|c|c|c|}
\hline Ueberimpfung nach & 10 Min. & $20 \mathrm{Min}$. & 30 Min & $45 \mathrm{Min}$. & 1 Std. & $11 / 4$ Std. & $1 \frac{1}{2}$ Std. & $2-4 \mathrm{St}$ \\
\hline $\begin{array}{l}1 / 4 \text { procentige } \\
\text { Carbolsäure }\end{array}$ & $\begin{array}{l}\text { sehr } \\
\text { reichl. }\end{array}$ & desgl. & desgl. & desgl. & desgl. & desgl. & desgl. & reichl. \\
\hline 1/4 proc. Kresol & $\begin{array}{l}\text { sehr } \\
\text { reichl. }\end{array}$ & desgl. & desgl. & reichl. & $\begin{array}{l}\text { zahlr. } \\
\text { einz. C. }\end{array}$ & desgl. & desgl. & 0 \\
\hline $\begin{array}{l}\text { 1/4 proc. Aethylen- } \\
\text { diamin-Kresol }\end{array}$ & $\begin{array}{l}\text { zahlr. } \\
\text { einz. C. }\end{array}$ & desgl. & spärl. & desgl. & s. spärl. & 0 & 0 & 0 \\
\hline
\end{tabular}

Gleichzeitig wurde derselbe Urin mit einer $1 / 2$ procentigen Solveollösung rersetzt; selbst nach vier Stunden indessen war kaum eine merkliche Abnahme der zur Entwickelung kommenden Keime zu constatiren; allerdings war ja auch der Kresolgehalt der geprüften (1/4 procentigen) Solveollösung fast vier Mal so gering als derjenige der beiden anderen Kresolpräparate. Ein entsprechender Versuch mit Sublimat 1:4000 lehrte, dass nach 4 Stunden die Mikroorganismen des Harns durch diese Lösung noch nicht abgetödtet waren.

Aus allen bisher mitgetheilten Versuchen geht nun mit überzeugender Deutlichkeit hervor, dass das Aethylendiaminkresol sämmtlichen anderen gleichzeitig geprüften Desinfectionsmitteln in hohem Mraasse überlegen ist, und dass der Zusatz des Aethylendiamins die bakterientödtende Kraft des Kresols sebr bedeutend erhöht, gleichriel ob dieselbe in eiweissfreien oder eiweisshaltigen Flüssigkeiten bestimmt wurde. Mit Berücksichtigung der bereits oben erwähnten Vorzüge scheint demnach das Aethylendiaminkresol geeignet, in die Desinfectionspraxis eingeführt zu werden und verspricht zweifellos auch bei der praktischen Anwendung mancherlei Vortheile zu bieten.

Es sind bereits zahlreiche Versuche an der hiesigen Klinik mit dem neuen Mittel gemacht worden, wobei sich das Präparat in mannigfacher Beziehung als sehr brauchbar erwies. Es hatte erheblich geringere Reizwirkung, als die anderen Antiseptica und eignete sich sehr gut zu feuchten Verbänden bei verschiedenartigen Geschwüren, beim Eczem und Lupus u. s. w. 
ÜBER D. DESINFECTIONSWERTH D. AETHYLENDIAMTNSILBERPHOSPHATS. 231

Nachdem nunmehr die Resultate der Desinfectionswersuche mitgetheilt worden sind, muss ich noch einmal auf die Technik derselben zurückkommen, um zwei Punkte genauer zu bespreehen.

Die erste hier zu berührende Frage bezieht sich auf die Reichlichkeit der Aufsehwemmung und auf den Einfluss, welchen dieselbe auf die Versuchsergebnisse ausübt. Dass ein solcher Einfluss thatsächlich vorhanden ist, wurde oben bereits kurz erwähnt; ich wurde auf diese Thatsache aufmerksam, als ich einzelne Desinfectionsversuche später wiederholte; es stellte sich hierbei heraus, dass das Verhältniss der so erhaltenen Werthe für die geprüften Desinfeetionsmittel unter einander dasselbe war; dass z. B. Aethylendiaminsilberphosphat die Prodigiosuskeime etwa $60 \mathrm{Mi}$ nuten früher abtödtete als Argentum nitric., dass jedoch die absoluten Zahlenwerthe nicht die gleichen waren, sondern etwas differirten. Da nun bei der Wiederholung eine Gleichheit der Versuchsbedingungen nach Mïglichkeit hergestellt worden war, so glaubte ich die Verschiedenheit der Resultate auf die verschiedene Reichlichkeit der Aufschwemmung zurückführen zu müssen, welche sich erklärlicher Weise nicht stets vollkommen vermeiden liess. Dass nun die Menge der zur Aufschwemmung verwandten Mikroorganismen eine wichtige Rolle bei den Desinfectionsarbeiten spielt, darauf ist mehrfach in der neueren Litteratur hingewiesen worden. So rechnet Behring in seiner mehrfach eitirten Abhandlung (2) zu den wichtigeren Falstoren, welche bei Desinfectionsexperimenten zu berücksichtigen sind, auch die Zahl der abzutödtenden Bakterien in dem Sinne, dass bei grösserer Zahl auch die Desinfection schwieriger ist. Ebenso sagt Boer in seiner oben erwähnten Arbeit (9), dass es keineswegs gleichgültig ist, ob viele oder wenige Bakterien abzutödten sind. Um nun diese Thatsache auch direct festzustellen und den Einfluss der Reichlichkeit der Aufschwemmungen auf die Ergebnisse zahlenmässig zu bestimmen, wurde absichtlich die Menge der Keime bei ein und demselben Desinfectionsversuch variirt, wobei sich heraustellte, dass die Dauer bis zur Abtödtung entsprechend schwankte.

\section{Desinfectionsversuche mit Aufschwemmungen von verschiedener Reichlichkeit.}

Drei Reagensgläschen werden mit $3^{\mathrm{ccm}}$ sterilen Wassers gefüllt. In das erste derselben (bezeichnet mit „I“) wurden 5 Oesen einer drei Tage alten Bouilloncultur von Prodigiosusbacillen übertragen, in das zweite „II" wurden fünf Tropfen derselben Cultur gebracht, in das dritte "III" 20 Tropfen. (Da hierbei in den drei Gläschen die Flüssigkeitsmenge, insbesondere die zugemischte Bouillon ungleich war, so wurden in Glas I 
18 Tropfen, in Glas II 15 Tropfen reiner Bouillon zugegossen.) Zu jeder der drei Aufschwemmungen wird eine ebenso grosse Menge Aethylendiaminsilberphosphat $(1: 2500)$ zugesetzt, so dass das Desinficiens in einer Concentration von 1:5000 auf Prodigiosuskeime in verdünnter Bouillon einwirkte.

Einwirkung von Aethylendiaminsilberphosphat 1:5000 auf verschieden reichliche Aufschwemmungen von Prodigiosusbacillen.

\begin{tabular}{|c|c|c|c|c|c|c|c|c|}
\hline Uebertragung nach: & $5 \mathrm{Min}$ & 10 yin. & 15 Min. & $20 \mathrm{Min}$ & 25 Min. & 30Min. & $40 \mathrm{Min}$ & 50-80 Min. \\
\hline $\begin{array}{c}\text { Glas I } \\
3^{\mathrm{ecm}} \text { sterilen Wassers mit } \\
5 \text { Oesen Prodig.-Bouillon } \\
\text { Glas II }\end{array}$ & + & + & 0 & 0 & 0 & 0 & 0 & 0 \\
\hline $\begin{array}{l}3^{\mathrm{ccm}} \text { sterilen Wassers mit } \\
5 \text { Tropfen Prod.-Bouillon }\end{array}$ & + & + & + & + & 0 & 0 & 0 & 0 \\
\hline $\begin{array}{c}\text { Glas III } \\
3^{\mathrm{ccm}} \text { sterilen Wassers mit } \\
20 \text { Tropfen Prod.-Bouillon }\end{array}$ & + & + & + & + & + & + & 0 & 0 \\
\hline
\end{tabular}

Aus diesem Versuch ist also mit grosser Deutlichkeit zu ersehen, dass je reichlicher die Aufschwemmung ist, desto später die Abtödtung der Prodigiosusbacillen gelingt, und dass die hierdurch bedingten Differenzen sehr erhebliche sind.

Ein ähnliches, gleichfalls sehr überzeugendes Resultat gab ein in gleicher Weise angestellter Desinfectionsversuch mit verschieden reichlichen Aufschwemmungen von Typhusbacillen. In ein Reagensglas mit $3^{\mathrm{com}}$ sterilen Wassers werden drei Tropfen einer drei Tage alten Typhusbouilloncultur, sowie 27 Tropfen Bouillon gebracht (Glas I), in ein zweites Glas mit $3 \mathrm{~cm}$ sterilen Wassers 30 Tropfen derselben Typhusbouillon; so dass die zweite Aufschwemmung etwa $10 \mathrm{mal}$ so reichlich war als die erste. In jedes Gläschen wird die gleiche Menge einer Höllensteinlōsung 1:2000 gegossen und im Zwischenraum von je fünf Minuten drei Oesen auf Agar übertragen.

Einwirkung von Argentum nitricum 1:4000 auf verschieden reichliche Aufschwemmungen ron Typhusbacillen in verdünnter Bouillon.

\begin{tabular}{|c|c|c|c|c|c|c|}
\hline Uebertragung nach: & 5 Min. & 10 Min. & 15 Min. & 20 Min. & 25 Min. & so Min. \\
\hline $\begin{array}{c}\text { Glas I } \\
\text { Aufschwemmung mit } \\
\text { 3 Tropf. Typhusbouill. }\end{array}$ & + & + & + & + & 0 & 0 \\
\hline $\begin{array}{c}\text { Glas II } \\
\text { Aufschwemmung mit } \\
\text { 30 Tropf. Typhusbouill. }\end{array}$ & + & + & + & + & + & + \\
\hline
\end{tabular}


ÜBER D. DESINGECTIONSWERTH D. AETHYLENDIAMINSILBERPHOSPHATS. 233

\begin{tabular}{c|c|c|c|c|c}
\multicolumn{6}{c}{ (Fortsetzung.) } \\
\hline \hline Uebertragung nach: & 35 Min. & 40 Min. & 50 Min. & 60 Min. & 70 Min. \\
\hline $\begin{array}{c}\text { Glas I } \\
\text { Aufschwemmung mit }\end{array}$ & 0 & 0 & 0 & 0 & 0 \\
3 Tropfen Typhusbouillon \\
$\begin{array}{c}\text { Glas II } \\
\text { Aufschwemmung mit } \\
\text { 30 Tropfen Typhusbouillon }\end{array}$ & + & + & + & 0 & 0
\end{tabular}

Die Thatsache selbst, dass eine reichliche Aufschwemmung einer Balterienart schwerer zu vernichten ist als eine spärliche, ist demnach ausser Zweifel; es fragt sich nun, welches der Grund für diese Erscheinung ist.

Ich glaube, dass es zwei Möglichkeiten giebt, welche als Erklärung dienen könnten.

Einmal könnte die in Rede stehende Erscheinung dadurch bedingt sein, dass das Desinficiens bei der Desinfectionsthätigkeit sich gewissermassen verbraucht. Es ist wohl zweifellos, dass der Vorgang der Bakterienabtödtung ein chemischer ist, und dass hierbei Umsetzungen der Desinfectionsflüssigkeit mit der Substanz der Mikroorganismen stattfinden. Hierbei muss nun - wie die Gesetze der Chemie lehren - ein gewisser Verbrauch unbedingt vor sich gehen. Es fragt sich nur, ob derselbe bei den nach unserer Methode angestellten Desinfectionsversuchen gross genug ist, um überhaupt in's Gewicht zu fallen, ob er bei Verwendung einer sehr reichlichen Mikroorganismensuspension so bedeutend ist, dass er die Desinfectionskraft der wirksamen Flüssigkeit merklich herabsetzt und so die langsamere Wirkung bedingt.

Ich habe nun mehrere Versuche angestellt, um diese Frage für unsere Versuchsanordnung zu entscheiden. Ich liess in der oben beschriebenen Weise eine Desinfectionsflüssigkeit von bestimmter Concentration auf eine sehr reichliche Bakterienaufschwemmung so lange einwirken, bis sichere Abtödtung erfolgt war. Nachdem dies geschehen war, brachte ich in dieselbe Flüssigkeit (welche also die Desinfectionsarbeit bereits einmal geleistet hatte) eine neue Menge der Mikroorganismen und constatirte nun, nach welcher Zeit die Abtödtung erfolgt war. Gleichzeitig wurde unter denselben Bedingungen der gleiche Desinfectionsversuch gemacht mit der gleichprocentigen Flüssigkeit, die noch nicht gewirkt hatte. Wäre nun in der That die Abschwächung der bakterientödtenden Eigenschaft durch die Desinfection eine merkliche, so müsste die Flüssigkeit, welche zum zweiten Male desinficirte, die zugesetzten Bakterien nach späterer Zeit abtödten, als eine gleichprocentige frische Lösung. Zahl- 
reiche in diesem Sinne angestellte Versuche haben stets ein negatives Resultat ergeben. Einzelne derselben sollen hier mitgetheilt werden.

In $3^{\mathrm{cm}}$ sterilen Wassers werden 20 Tropfen einer reichlich gewachsenen Bouilloncultur von Bacillus prodigiosus gebracht, in ein zweites Reagensglas mit $3^{\mathrm{cm}}$ sterilen Wassers $20^{\mathrm{ccm}}$ reiner Bouillon (Glas $I$ ), und nun in beide Gläser eine gleiche Menge (also $3 \mathrm{~cm}$ und 20 Tropfen) Aethylendiaminsilberphosphat 1:2000 zugesetzt. Nach 3/4 Stunden war nun - wie aus früheren Versuchen bekannt war - Abtödtung der Keime in Glas I sicher erfolgt, was übrigens auch durch Abimpfung auf Agar bestätigt wurde. Nach Verlauf dieser Zeit wurden zu Glas I und II je 10 Tropfen der Prodigiosusbouilloncultur zugesetzt, die Mikroorganismen demgemäss in beiden Fällen dem Desinficiens in gleicher Concentration und unter denkbar gleichen Bedingungen exponirt mit. dem einzigen Unterschiede, dass die Lösung in Glas I bereits zum zweiten Male den Kampf mit den Bakterien aufnahm (und - was wohl ohne Bedeutung ist - die todten Mikroorganismen und deren Stoffwechselproducte enthielt.)

Es zeigte sich nun, dass die Desinfection im Reagensglas I nicht später erfolgte als beim Parallelversuch, sondern genau zur gleichen Zeit, ${ }^{\mathbf{1}}$ woraus also hervorgeht, dass die desinficirende Lösung durch die Abtödtung der ungeheuren Zahl von Prodigiosuskeimen, die in 20 Tropfen der Bouilloncultur enthalten waren, keine merkliche Abschwächung erfahren hatte.

Das gleiche Resultat ergab sich bei einem in derselben Weise angestellten Versuche mit Bacillus pyocyaneus. Es stellte sich heraus, dass die Silberphosphatlösung, welche bereits desinficirt hatte, nicht schwächer wirkte als die frische Lösung. Ein gleiches liess sich constatiren bei zwei anderen Versuchen mit Arg. nitr. gegenüber Bacillus prodigiosus und pyocyaneus. Um nun die Anwesenheit der Stoffwechselproducte, welche bei obiger Versuchsanordnung (Verwendung von Bouillonculturen zur Aufschwemmung) vielleicht einen Versuchsfehler bedingen konute, nach Möglichkeit auszuschalten, habe ich noch zwei Versuche in der Weise vorgenommen, dass ich die Aufschwemmungen durch Abschaben von Prodigiosusagarculturen und Uebertragen in steriles Wasser herstellte. Sonst war die Versuchsanordnung die gleiche; es wurden Versuche mit Arg. nitr. sowohl als auch Silberphosphat gemacht. In beiden Fällen war wiederum eine Abschwächung der Desinfectionskraft durch die Desinfectionsthätigkeit nicht nachweisbar. ${ }^{2}$

Diese Versuche stützen somit die vorhin angeführte Erklärung nicht. Hiermit soll nicht etwa behauptet werden, dass ein Desinfectionsverbrauch überhaupt nicht stattfindet oder gar keinen Einfluss auf das Desinfectionsresultat übt; ich ziehe aus den obigen Versuchen nur den Schluss, dass derselbe bei unserer Versuchsanordnung nicht ausreichend ist, um die in Frage stehende Erscheinung allein zu erklären; vielmehr muss für dieselbe noch eine andere Ursache und Begründung beigebracht werden.

\footnotetext{
1 Nämlich nach 30 Min.; überimpft wurde in Zwischenräumen von je 5 Min.

2 Im Uebrigen gaben die Versuchsresultate eine Bestätigung der in den Tabellen angegebenen Zahlenwerthe.
} 
ÜBER D. DESINFECTIONSWERTH D. AETHYLENDIAMINSILBERPHOSPHATS. 235

Diese könnte nun vielleicht in Folgendem gesucht werden. Bekanntlich haben die einzelnen Individuen einer Bakterienaufschwemmung keineswegs gleiche Resistenz, wie dies z. B. Geppert für die Milzbrandsporen gegenüber der Einwirkung von kochendem Wasser und Chlor und auch andere Autoren nachgewiesen haben. Auch aus der Betrachtung der oben stehenden Tabellen geht dies mit Sicherheit hervor, da beim Ueberimpfen nach verschieden langer Expositionsdauer das Wachthum nicht plötzlich aufhörte, sondern ganz allmählich spärlicher wurde, um schliesslich vollständig aufzuhören. Bei durchaus gleicher Resistenz der einzelnen Mikroorganismen müsste nothwendiger Weise die Vernichtung derselben zu ein und derselben Zeit erfolgen, vorausgesetzt, dass das Desinficiens gleichzeitig und ungehindert auf sāmmtliche Bakterien wirken konnte, was ja bei unseren Versuchen mikroskopischer Untersuchung zu Folge thatsãchlich der Fall war.

Die Thatsache der allmählichen Abtödtung habe ich auch zahlenmässig bestimmt, indem ich mich nicht auf die Ueberimpfung auf Agar beschränkt habe, sondern durch das Plattenverfahren die Zahl der lebensfähigen Keime nach verschiedenen Zeiträumen feststellte.

$3^{\mathrm{ecm}}$ einer sehr reichlichen Aufschwemmung von Prodigiosusbacillen in verdünnter Bouillon werden mit gleichen Theilen Aethylendiaminsilberphosphat $1: 2000$ versetzt; in Zeiträumen von je fünf Minuten werden drei Oesen in flüssige Gelatine übertragen und zur Platte ausgegossen. Die Zählung der nach verschiedener Expositionsdauer gewachsenen Colonieen gab folgendes Resultat:

$\begin{array}{crrrrr}\text { Uebertragung nach } & 1 & \text { Min. unzählige } & \text { Colonie } \\ " & " & 5 & " & 60480 & " \\ " & " & 10 & " & 8704 & " \\ " & " & 15 & " & 62 & " \\ " & " & 20 & " & 0 & "\end{array}$

Bei einem gleichen Versuch mit Arg. nitr. 1:4000 war gleichfalls eine sehr deutliche Abnahme der nach verschiedener Zeitdauer gewachsenen Colonieen bemerkhar, die Zählung jedoch wegen der sehr bald eingetretenen Verflüssigung meist unmöglich.

Ein entsprechender Versuch mit einer Aufschwemmung von Typhusbacillen, welche einer Arg. nitr.-Lösung 1:4000 ausgesetzt wurden, ergab folgende Zahlen:

\begin{tabular}{|c|c|c|c|c|c|}
\hline Uebertragung & nach & h 1 & Min. & 927440 & Coloniee \\
\hline$"$ & $n$ & 5 & $\eta$ & 3932 & $"$ \\
\hline " & $"$ & 10 & $n$ & 49 & $"$ \\
\hline$"$ & $"$ & 20 & $"$ & 5 & $n$ \\
\hline$n$ & $"$ & 30 & $n$ & 0 & 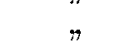 \\
\hline
\end{tabular}

Nach den mitgetheilten Versuchen ist es unzweifelhaft, dass die Resistenz der einzelnen Individuen einer Bakterienaufschwemmung eine ungemein verschiedene ist, dass zahlreiche Mikroorganismen sich sehr 
leicht abtödten lassen, andere wieder der Einwirkung des Desinficiens viel länger widerstehen. Es ist nun klar, dass eine relatir spärliche Aufschwemmung, die zwar noch ungemein viel lebensfähige Keime überhaupt enthält, nur wenige von den resistentesten bergen kann, eine sehr reichliche dagegen zahlreiche Individuen von grösster Widerstandsfähigkeit. Im ersten Fall ist dementsprechend bei einem Desinfectionsversuch die Wahrscheinlichkeit, dass man beim Uebertragen resistentere Individuen auf den neuen Nährboden bringt, eine geringe, im zweiten Fall eine viel grössere. Auf diese Weise könnte man dann die Thatsache erklären, dass bei einer spärlichen Aufschwemmung die Abtödtung scheinbar schneller erfolgt, als bei einer reichlichen.

An letzter Stelle muss ich noch auf einen Punkt zu sprechen kommen, dessen Bedeutung oben bereits kurz erwähnt wurde, und welcher wohl zu den wichtigsten in der Desinfectionstechnik überhaupt gehört. Es ist dies die Frage, in wie weit der Versuchsfehler der Mitübertragung ron Desinficiens auf den neuen Nährboden die Resultate des Experiments beeinflusst und die Richtigkeit der Ergebnisse beeinträchtigt.

Es ist das Verdienst Geppert's auf diese Fehlerquelle aufmerksam gemacht und in überzeugender Weise nachgewiesen zu haben, dass aus derselben unrichtige Vorstellungen über die Desinfectionskraft ron Sublimatlösungen gegenüber Milizbrandsporen resultirten. Bekanntlich hat Geppert durch Zusatz von Schwefelammonium zum Quecksilberchlorid also durch chemische Unschädlichmachung den genannten Versuchsfehler vermieden und so die Resultate des Desinfectionsexperimentes richtig gestellt. Wie oben bereits auseinandergesetzt, ist auch bei unseren Desinfectionsversuchen der in Frage stehende Fehler gemacht worden, da bei der Ueberimpfung aus der Bakteriensuspension auch Spuren des Desinficiens auf den Nährboden gebracht wurden. Es ist zwar an der gleichen Stelle darauf hingewiesen worden, dass aus mehreren Gründen die Fehlerquelle eine nicht sehr bedeutende sein konnte, indessen war es doch wünschenswerth dies auch direct zu beweisen und darzuthun, dass der bei unserer Versuchsanordnung begangene Fehler thatsächlich die Richtigkeit der Resultate nicht beeinträchtigte. Nur unter dieser Bedingung war die $\mathrm{Me}$ thode als einwandfreie $z u$ bezeichnen.

Es war nun mein Bestreben eine Methode zu fipden, mit deren Hülfe es gelingt, die Mitübertragung des Desinficiens zu vermeiden und den Nachweis zu führen, dass die so gewonnenen Zahlenwerthe von den 
ÜBER D. DESINFECTIONSWERTH D. AETHYLENDIAMINSILBERPHOSPHATS. 237

oben erhaltenen nicht abweichen, dass also die Resultate der mitgetheilten Desinfectionsversuche richtig sind und der Versuchsfehler somit unberücksichtigt bleiben konnte.

Wie aus der im Anfange geschilderten Versuchsanordnung erinnerlich ist, wurde die gelungene Desinfection in der Weise festgestellt, dass nach der gewünschten Expositionsdauer drei Platinösen aus der mit dem Desinficiens versetzten Aufschwemmung auf Agar oder in Bouillon übertragen wurden; es wurden hierbei also mit den Bakterien zugleich anch Spuren des Desinfectionsmittels auf den neuen Nährboden gebracht. Nun ist es einleuchtend, dass in Folge dessen - besonders beim Uebertragen auf Agar - das Desinficiens noch länger a uf die Mikroorganismen wirkte und die Entwickelung der überimpften Keime hemmen konnte, wie dies ja nach den oben mitgetheilten Vorversuchen mit den Nährböden, denen Arg. nitr., Silberphosphat u. s. w. zugesetzt worden waren, gegenüber den frischen Bakterienculturen möglich war. Wahrscheinlich kommt dieser entwickelungshemmende Einfluss in noch viel höherem Maasse zur Geltung, wenn es sich um Mikroorganismen handelt, welehe bereits durch die Einwirkung des betreffenden Desinficiens geschädigt und in ihrer Resistenzfähigkeit geschwächt waren. Es waren demgemäss möglicher Weise die gefundenen Resultate ungenau und zwar in dem Sinne, dass günstigere Resultate vorgetäuscht wurden. Wenn sich z. B. herausgestellt hatte, dass bei Einwirkung einer $1 / 4$ procentigen Aethylendiaminkresollösung nach 20 Minuten Bacillus prodigiosus noch wuchs, nach 30 Minuten jedoch nicht mehr, so war das erstere beweisend für die noch nicht erfolgte Abtödtung der Bakterien - vorausgesetzt, dass die Aufschwemmung fein genug war, und dass zu sämmtlichen Mikroben die Flüssigkeit hingelangen konnte, was ja in jedem einzelnen Falle durch das Mikroskop bestätigt wurde -, die zweite Thatsache aber, das Ausbleiben des Wachsthums nach 30 Minuten Expositionsdauer, war nicht einwandfrei, da vielleicht die übertragene Probe auf einem von Desinficiens vollständig freien Nährsubstrat noch zur Entwickelung gekommen wäre.

Wie aber sollte man diesen Versuchsfehler vermeiden? Bei manchen Desinficientien lässt sich dies nach Geppert's Vorgange durch chemische Fällung erreichen. Experimentirt man z. B. mit Sublimatlösung, so kann man durch Zusatz von Schwefelammonium die Mikroorganismen fast augenblicklich dem Einfluss des Desinficiens entziehen, und ferner überträgt man beim Ueberimpfen nur das völlig unschädliche Schwefelquecksilber und allenfalls Spuren des wenig wirksamen Schwefelammoniums. In derselben Weise lässt sich das Arg. nitr. unschädlich machen, wenn nicht etwa das bei Vermischung mit Schwefelammonium entstehende salpetersaure Ammonium störende antiseptische Eigenschaften besitzt. 
Indessen ist doch die Zahl der Fälle, wo diese Methode der chemischen Unschädlichmachung Anwendung finden kann, relativ beschränkt; bei sehr zahlreichen Desinficientien, insbesondere aber bei complicirten, organischen Verbindungen (z. B. auch bei den von mir geprüften Desinfectionsflüssigkeiten) ist dies nicht möglich, weil wir keine Mittel kennen, dieselben in unwirksame Verbindungen überzuführen. Sucht man nun den in Rede stehenden Uebelstand dadurch zu vermeiden, dass man die mit dem Desinficiens versetzte Aufschwemmung nach bestimmter Zeit sehr verdünnt und hiervon überimpft, so ist zwar die mit übertragene IIenge des Antisepticums geringer und der betreffende Versuchsfehler hleiner; praktisch jedoch waren die Resultate noch ungenauer und zwar wohl deshalb, weil bei dieser Versuchsanordnung viel weniger Mikroorganismen übertragen wurden, was nach dem im vorigen Abschnitt Gesagten durchaus nicht gleichgültig sein kann. Meist blieb das Wachsthum viel früher aus, als bei directer Ueberimpfung aus der ursprünglichen Aufschwemmung.

Da nun mit Hülfe der bisher bekannten Methoden der betreffende Uebelstand nicht zu vermeiden war, so versuchte ich auf folgendem Wege das gewünschte Ziel zu erreichen. Ich nahm an, dass der Versuchsfehler sich ausschalten lassen müsste, wenn es gelänge, die Bakterien nach einer gewissen Zeit von der Desinfectionsflüssigkeit zu trennen; man könnte alsdann dieselben in sterilem Wasser aufschwemmen und auf den Nährboden überimpfen, ohne das Desinficiens mit zu übertragen. Ich glaubte dies vielleicht durch Centrifugiren der Bakterien erreichen zu können. Sollte z. B. eine Aufschwemmung von Mikroorganismen 20 Minuten lang einem Desinficiens ausgesetzt werden, so müsste nach dieser Zeit die Aufschwemmung centrifugirt, die überstehende Flüssigkeit abgegossen, und der Bodensatz mit sterilem Wasser aufgesehwemmt werden. Ich hätte dann die Bakterien nach einer bestimmten Expositionsdauer dem Desinficiens entzogen und könnte nun durch Ueberimpfen die Uebertragung auf den neuen Nährboden vornehmen.

Selbst wenn es nun gelingen würde, die Mikroorganismen auszucentrifugiren, so wären noch zwei Punkte besonders zu berücksichtigen.

Erstens erfordert das Ausschleudern einige Zeit, so dass hieraus eine Ungenauigkeit entstehen könnte, zweitens haftet dem Auscentrifugirten noch etwas von der Desinfectionsflüssigkeit an, so dass die neue Aufschwemmung Spuren des Desinficiens, wenn auch in äusserst schwacher Verdünnung, enthalten würde.

Auf diese beiden Punkte will ich später eingehen und zuerst die Frage des Centrifugirens von Bakterien besprechen.

In erster Reihe war zu untersuchen, ob es überhaupt möglich ist, in Flüssigkeit frei suspendirte Mikroorganismen mit Hülfe 
ÜBER D. DESINFECTIONSWERTH D. AETHYLENDIAMINSILBERPHOSPHATS. 239

der Centrifuge auszuschleudern. Dass man nicht berechtigt ist, dies von vornherein anzunehmen, ergiebt sich aus folgender Ueberlegung. Beim Ausschleudern irgend welcher körperlichen Elemente aus einer Flüssigkeit sind wesentlich folgende Factoren massgebend:

1. die durch die Rotationsgesehwindigkeit bedingte Centrifugalkraft,

2. die Schwere der zu centrifugirenden Körper,

3. der Widerstand, welchen die Flüssigkeit der Bewegung der Partikelchen entgegensetzt.

Je grösser nun die beiden ersten Factoren, um so leichter, je grösser der letzte Factor, um so schwerer wird das Auscentrifugiren möglich sein. Es ist also sehr wohl denkbar, dass das Product aus 1 und 2 zu klein ist, um den Factor 3 zu überwinden. So ist es z. B. klar, dass ein sehr leichter Niederschlag (etwa Semen Lycopodii) in einer zähen, syrupösen Flüssigkeit nicht auszuschleudern sein wird. Aehnlich verhält es sich nun auch bei dem Versuche, Mikroorganismen, welche in Wasser aufgeschwemmt sind, auszucentrifugiren; dies ist, wie ich bei zahlreichen Experimenten mit versehiedenen Bakterienarten gesehen habe, nur sehr unvollkommen möglich. Als Grund hierfür glaube ich annehmen zu müssen, dass bei dem äusserst geringen Gewicht der Mikroben das Product aus den ersten beiden Factoren zu klein ist, um den Widerstand des Wassers überwinden zu können. Die Versuchsanordnung zur Prüfung der Frage, ob Mikroorganismen sich centrifugiren lassen und in welchem Naasse, war folgende: In ein sterilisirtes Centrifugenröhrchen von cylindrischer Gestalt mit spitz zulaufendem unteren Ende wurden $10^{\mathrm{ccm}}$ einer möglichst feinen Bakterienaufschwemmung in sterilem Wasser gebracht, mit Wattepfropf versehen und zweimal je zwei Minuten mit der Gärtner'schen Centrifuge ausgeschleudert. Alsdann werden aus dem oberen Theil der Flüssigkeit drei Platinösen entnommen und mit flüssiger Gelatine in gewöhnlicher Weise zur Platte ausgegossen. Hierauf wird mit steriler Pipette die überstehende Flüssigkeit abgehoben, und aus dem in der unteren Spitze des Röhrchens befindlichen Rest werden wiederum drei Platinösen zur Platte ausgegossen. Zählte man nun die ausgewachsenen Colonieen, so bekam man die Zahl der Keime, welche enthalten waren in drei Oesen der oben befindlichen bezw. der am Boden gebliebenen Flüssigkeit. Wären nun die Bakterien vollständig auscentrifugirt worden, so hätten naturgemäss auf der ersten Platte keine Colonieen wachsen dürfen. Dies war keineswegs der Fall; vielmehr war der Untersehied der Colonieen auf Platte I und II ein verhältnissmässig geringer, wie zahlreiche Versuche mit verschiedenen Bakteriensuspensionen lehrten. Von diesen sollen nur die mit Typhusbacillen erhaltenen Zahlen, welche etwa die Mittelwerthe der versehiedenen Versuchsresultate darstellen, mitgetheilt werden. 
Nach zweimaligem Ausschleudern waren in drei Oesen, welche aus der Mitte des Gläschens entnommen waren, 1293280 Keime nachweisbar, während drei Platinösen aus der am Boden des Röhrchens befindlichen Flüssigkeit $\Sigma 269440$ Typhusbacillen enthielten. Bei einem gleichen Versuch mit einer spärlichen Aufschwemmung ergaben sich durchaus ähnliche Zahlenwerthe nämlich: 109086 bezw. 258506 Colonieen.

Aus diesen und ähnlichen Versuchen, die an verschiedenen Mikroorganismen angestellt wurden, war nun ersichtlich, dass die Bakterien nur in höchst unvollkommener Weise sich auschleudern liessen, jedenfalls viel zu wenig, als dass diese Methode für unsere Zwecke, nämlich die Mikroorganismen von der Desinfectionsflüssigkeit zu trennen, anwendbar gewesen wäre.

Ich versuchte daher der Aufschwemmung ein fein vertheiltes Pulver beizumischen und durch dieses die Bakterien herabreissen zu lassen. Ein solches Pulver musste folgende Bedingungen erfüllen. Es musste mit Wasser eine Aufschwemmung geben und sich vollständig auscentrifugiren lassen; zweitens mit Sicherheit sich sterilisiren lassen und drittens den Mikroorganismen gegenüber völlig indifferent sein. Mehrere anorganische und organische Stoffe wurden daraufhin geprüft unter anderen Glasstaub, fein gestossener Sand, Schwefelblume und Semen Lycopodii; indessen entsprach keiner derselben den geforderten Bedingungen. Dagegen erwiesen sich Kieselguhr, besonders aber gebeutelter Talk als zweckmässig und brauchbar. Diese beiden Pulver liessen sich mit Wasser aufschwemmen und leicht auscentrifugiren, konnten durch Dampfhitze leicht sterilisirt werden und waren, wie noch durch besondere Versuche nachgewiesen wurde, den Mikroorganismen völlig unschädlich. ${ }^{3}$ Um nun zu sehen, in wie weit mit Hülfe dieser Pulveraufschwemmungen die Keime zu centrifugiren waren, wurden die Bakteriensuspensionen mit dem Pulver vermischt, wie oben centrifugirt und die Zahl der Keime in der überstehenden Flüssigkeit, sowrie im Sediment festgestellt; es ergaben sich hierbei sehr erhebliche Unterschiede.

Aufschwemmungen von Typhusbacillen in sterilem Wasser mit Kieselguhr entbielten nach zweimaligem Ausschleudern in drei Oesen der überstehenden Flüssigkeit 29376 Keime, in drei Oesen des Sediments 173880.

Beim Centrifugiren mit Talk

oben: 168832 Keime

im Sediment: 1043792

1 Auch das Centrifugiren in wässeriger Aufschwemmung, selbst wenn dasselbe absichtlich längere Zeit vorgenommen wurde, schädigte die Hikroorganismen nicht nachweislich. 
ÜbFR D. DesinfeCtTonswerth D. AETHYLENDIANINSILBERPhoSPHATS. 241

Bei einer reichlicheren Aufschwemmung

oben: 495488 Keime

unten: 4402742 ",

Bei einer Aufschwemmung von Bacill. pyocyaneus war das Ergebniss der Zählung

oben: 96524 Keime

unten: 1329148

Bei einer Diphtherieaufschwemmung

oben: 17560 Keime

unten: 350832

Wie man sieht, war die Anzahl der Keime im Sediment stets erheblich grösser als in der überstehenden Flüssigkeit, indess war doch das Verhältniss zwischen beiden Zahlen in den einzelnen Fällen ein sehr schwankendes, was wohl hauptsächlich auf die Ungenauigkeit der Methode zur Bestimmung der Bakterienzahl zurückzuführen war. Diese konnte nur ganz approximative Vergleichswerthe liefern, da in dem einen Falle drei Oesen einer Flüssigkeit, im zweiten Falle drei Oesen eines angefeuchteten Pulvers übertragen wurden. Besser übereinstimmende Resultate wurden gefunden, als die Anzahl der Likroorganismen in der Originalaufschwemmung und in der zweiten verglichen wurde. Letztere wurde so hergestellt, dass nach dem Auscentrifugiren die überstehende Flüssigkeit abgegossen und das Sediment mit $10^{\mathrm{ccm}}$ sterilen Wassers aufgeschüttelt wurde. Es zeigte sich hierbei, dass die zweite Aufschwemmung durchschnittlich den dritten Theil der Bakterienzahl der ursprünglichen Aufschwemmung enthielt. Die Zahlenwerthe, welche in derselben Weise wie oben mittels des Plattenverfahrens bestimmt wurden, waren folgende:

Wässerige Aufschwemmung von Typhusbacillen mit Talk.

Zahl der Keime in der I. Aufschwemmung 319004.

$$
\text { " " " "II. " }
$$

Spärlichere Aufschwemmung von Typhusbacillen mit Talk in sterilem

Wasser.

I. Aufschwemmung enthielt (in 3 Oesen): 120960 Bakterien

II.

$$
" \quad " \quad, \quad 39312 \quad,
$$

Aufschwemmung von Bacill. prodig. mit Talk in sterilem Wasser.

I. Aufschwemmung: 612840 Bakterien

II. $\quad 279726 \quad "$

Aufschwemmung von Diphtheriebacillen in sterilem Wasser mit Talk:

I. Aufschwemmung: 64992 Bakterien

II.

$$
" \quad 30560
$$

Zeitschr. f. Hygiene, XVI.

" 16


Die mitgetheilten Zahlen sind nur Grenzwerthe aus einer längeren Reihe von Untersuchungen, aus denen hervorging, dass die zweite Aufschwemmung die Hälfte bis ein Viertel durschnittlich etwa den dritten Theil der Mikroorganismen der Originalsuspension enthielt, die nächste Aufschwemmung, welche in gleicher Weise durch nochmaliges Centrifugiren erhalten wurde, wiederum $1 / 3$ der vorhergehenden $u$. s. f.

Nachdem also auf diese Weise die Möglichkeit gegeben war, die Bakterien - wenigstens grossentheils - auszucentrifugiren, gestaltete sich die Versuchsanordnung folgendermassen:

Genau in der früher geschilderten Weise wird die Bakterienaufschwemmung mit dem betreffenden Desinficiens gemischt und eine bestimmte Zeit lang der Einwirkung desselben ausgesetzt. Gegen Ende dieser Zeit wird nach Zusatz des Talks das Centrifugiren in den hierzu bestimmten Röhrchen vorgenommen, nach Ablauf der Expositionsdauer die überstehende Flüssigkeit abgegossen und durch Hinzufügung von $10 \mathrm{~cm}$ sterilen Wassers eine neue Aufschwemmung hergestellt. ${ }^{1}$

Von dieser Aufschwemmung wird die Uebertragung auf den neuen Nährboden, z. B. Nährbouillon, vorgenommen, so dass sich jetzt die Bakterien, nachdem sie eine genau gemessene Zeit dem zu prüfenden Mittel ausgesetzt waren, in einem Nährmedium befinden, welches vom Desinficiens nur die allerminimalsten Spuren enthält.

Diese sollen nun zahlenmässig bestimmt werden. Um den Gehalt an Desinfectionsflüssigkeit für die zweite Aufschwemmung zu berechnen, muss man die Flüssigkeitsmenge im centrifugirten Sediment kennen. Ich erreichte dies dadurch, dass ich das Gerricht des Centrifugengläschens mit dem feuchten Sediment unmittelbar nach dem Abgiessen der überstehenden Flüssigkeit bestimmte, im Brütofen und Exsiccator dasselbe röllig austrocknete und wiederum wog. Die Differenz dieser beiden Grössen gab die Menge der mitübertragenen Desinfectionsflüssigkeit an; dieselbe schwanlite von 0.0431 bis $0.0902 \mathrm{grm}$, erreichte also in keinem Falle $0 \cdot 1 \mathrm{grm}$. Nehme ich jedoch diese zu hoch gegriffene Zahl als das gewöhnliche an, so wird die Verdünnung in den $10^{\mathrm{ccm}}$ Wasser $100 \mathrm{mal}$ so gross; übertrage ich nun von hier drei Oesen in die Bouillon (z. B. $15^{\mathrm{com}}$ ) so be-

1 Da das Ausschleudern etwa 4 Minuten dauert, waren die Mikroorganismen eine Zeit lang nicht in der Flüssigkeit suspendirt, sondern mit dem Pulver am Boden des Röhrchens niedergeschlagen; sie sind natürlich wäbrend dieser Zeit keineswegs der Einwirkung des Desinficiens entzogen, sondern annähernd in gleicher Weise demselben exponirt, da ja das Sediment vollständig durchfeuchtet ist von der Desinfectionsflüssigkeit in derselben Concentration. Dem abtödtenden Einfluss des Mittels werden die Bakterien in dem Augenblick entzogen, wo sie mit dem sterilen Wasser wieder anfgeschüttelt werden. 
trägt die abermalige Verdünnung wiederum das 100 fache. Hatte ich also ursprünglich - wie bei den meisten oben angeführten Desinfectionsversuchen - mit einer Concentration von 1:4000 zu thun, so beträgt die Verdünnung im Nährboden 1:40000000. Durch zweimaliges Centrifugiren kamn man die Verdünnung noch entsprechend vermehren nämlich auf $1: 4000000000$ u. s. w.; indessen erscheint dies zahlreichen Versuchen zu Folge völlig überflüssig.' Verwendet man ursprünglich eine 1 procentige Lösung, so würde der Gehalt der Bouillon an Desinficiens höchstens 1:100000000 betragen, wenn zweimal centrifugirt wurde. Solche Verdünnungen, wie sie mit Hülfe der Centrifugirungsmethode erreicht werden, können nun selbst bei Versuchen mit den stärksten Desinficientien ausser Acht gelassen werden.

Ehe ich zur praktischen Verwerthung lieser neuen Methode übergehe, scheint es mir wünschenswerth, dieselbe auf ihre Leistungsfähigkeit zu prüfen und den Nachweis zu führen, dass man thatsächlich im Stande ist, mit Hülfe derselben die Uebertragung von Desinficiensspuren zu vermèiden, bezw. auf ein äusserst geringes Maass einzuschränken. Am geeignetsten hierfür schien ein directer Vergleich mit der von Geppert angegebenen Methode der chemischen Unschädlichmachung, welche erwiesenermassen das gewünschte Ziel erreichte. Als zweckmässiges Object für eine solche Untersuchung boten sich die Vilzbrandsporen dar, welehe sich gegen die geringsten Spuren von Sublimat äusserst empfindlich zeigten, und bei denen die Uebertragung von sehr kleinen Mengen des Quecksilberchlorids bereits erhebliche Unterschiede im Resultat ergab. Die Versuchsanordnung gestaltete sich nun folgendermassen. Es wird eine grössere NLenge einer reichlichen, wässerigen Aufschwemmung von Milzbrandbacillen und Sporen hergestellt. Ein Theil derselben wird mit der gleichen Menge Sublimatlösung 1:500 versetzt; hiervon werden in der gewöhnlichen Weise nach verschiedenen Zeiträumen drei Oesen in Bouillon übertragen. Ein anderer Theil der Aufschwemmung wird gleichfalls mit der Sublimatlösung gemischt; nach verschiedener Expositionsdauer wird je $1^{\mathrm{cem}}$ des Gemisches mit Sehwefelammonium behandelt und hieraus die Ueberimpfung vorgenommen. Endlich wird ein

1 Es ist klar, dass bei Anwendung dieser Methode die auf den neuen Nährboden übertragene Probe weniger Keime enthält, als bei directer Ueberimpfung aus der ursprünglichen Aufschwemmung. Will man aber annähernd dieselbe Bakterienanzahl auf ihre Entwickelungsiähigkeit prüfen, so kann man etwa 5 oder 15 Tropfen der zweiten bezw. dritten Aufschwemmung übertragen, wobei die Verdünnung immer noch gross genug bleibt, um vernachlässigt werden zu können. Bei den nachfolgenden Versuchen habe ich sowohl drei Oesen als auch 5 bezw. 15 Tropfen übertragen, jedoch in allen Fällen gleiche Resultate erhalten. 
dritter Theil derselben Sporensuspension zu einem gleichen Desinfectionsversuch unter Anwendung der Centrifugirungsmethode benutzt. Die Resultate waren folgende:

Wässerige Aufschwemmung von Milzbrandsporen, exponirt einer Sublimatlösung 1:1000.

\begin{tabular}{c||c|c|c|c|c|c|c|c}
\hline Expositionsdauer: & 5 Min. & $10 \mathrm{M}$ & $15 \mathrm{M}$ & $20 \mathrm{M}$ & $30 \mathrm{M}$ & 1 Std. & 2 Std. & 3 Std. \\
\hline $\begin{array}{c}\text { Directe Uebertragung } \\
\text { Uebertragung nach Fällung } \\
\text { des Sublimats durch } \\
\text { Schwefelammonium } \\
\begin{array}{c}\text { Uebertragung } \\
\text { mit Anwendung der } \\
\text { Centrifugirungsmethode }\end{array}\end{array}$ & +5 & + & + & 0 & 0 & 0 & 0 & 0 \\
& & + & & + & + & + & + & 0 \\
\end{tabular}

Aus dieser Tabelle geht nun hervor, dass in der That bei einem Desinfeetionsversuch mit 0.1 procentiger Sublimatlösung die directe Uebertragung aus der Originalaufschwemmung die Resultate sehr ungenau macht, dass sich der Veruchsfehler jedoch vermeiden lässt sowohl durch die Methode der ehemischen Unschädlichmachung als auch durch die Centrifugirungsmethode, und dass dieselben hierbei anscheinend gleichwerthig sind.

Aehnlich fiel ein Versuch mit einer Aufschwemmung ron Prodigiosusbacillen aus, welche einer 0.1 procentigen Sublimatlösung exponirt und alsdann direct, nach Zusatz von $\mathrm{Am}_{2} \mathrm{~S}$ und nach Anwendung der Ceutrifugirungsmethode übertragen wurden.

Wässerige Aufschwemmung von Prodigiosusbacillen, exponirt einer Sublimatlösung 1:1000.

\begin{tabular}{c||c|c|c|c|c}
\hline \hline Expositionsdauer: & 2 Min. & 5 Min. & 10 Min. & 20 Min. & 30 Min. \\
\hline Directe Uebertragung & + & 0 & 0 & 0 & 0 \\
Uebertragung nach Zusatz & & + & + & 0 & 0 \\
$\begin{array}{c}\text { des Amertragung nach Anwen- } \\
\text { dung der Centrifugirungs- } \\
\text { methode }\end{array}$ & + & + & 0 & 0
\end{tabular}

Auch hier sprachen die Resultate dafür, dass zur Vermeidung des Versuchsfehlers die Centrifugirungsmethode ebenso geeignet und zweckmässig war, als diejenige der chemischen Unschädlichmachung, und dass sie ebenso genaue Ergebnisse lieferte. 
Nachdem nunmehr die Brauchbarkeit der neuen Methode erwiesen war, konnte ich dazu übergehen, dieselbe auch praktisch zu verwerthen; sie sollte - wie erinnerlich - dazu dienen, unsere Desinfectionsversuche auf ihre Richtigkeit $z \mathfrak{u}$ prüfen und $z u$ entscheiden, ob der bei denselben gemachte Versuchsfehler etwa falsche Ergebnisse bedingte. Ich habe dies so gemacht, dass ich mehrere der früheren Versuche in der gewöhnlichen Weise wiederholte, gleichzeitig aber mit Hülfe der neuen Methode den Fehler auschaltend eine Controle der Resultate vornahm. So hatte ich z. B. bei dem an erster Stelle mitgetheilten Desinfectionsversuch mit Aethylendiaminsilberphosphat gefunden, dass Prodigiosusbacillen nach 20 Mlinuten abgetödtet waren. Ich überimpfte also in der gewöhnlichen Weise nach 10, 20 Minuten u. s. w. direct aus der Originalaufschwemmung; ebenso wurde nach denselben Zeiträumen unter Anwendung der Centrifugirungsmethode die Desinfectionsprüfung vorgenommen. Hatte nun der Versuchsfehler thatsächlich falsche Ergebnisse geliefert, so müsste im zweiten Falle, d. h. bei Vermeidung der Fehlerquelle noch nach längerer Expositionsdauer Wachsthum beobachtet werden. Dies war jedoch nicht der Fall, vielmehr gaben beide Methoden durehaus übereinstimmende Resnltate; in beiden Fällen hörte das Wachsthum zum ersten Male nach 20 Minuten Expositionsdauer auf. In gleicher Weise habe ich noch folgende Desinfectionsversuche nachgeprüft:

Desinfectionsversuch mit einer Aufschwemmung von Bacillus prodigiosus gegenüber der Einwirkung von Arg. nitr. 1:4000, 1/4 Procent Kresol, $1 / 2$ Procent Kresol und 1/4 Procent Aethylendiaminkresol. Ferner Desinfectionsversuche mit Bacill. pyocyan. gegenüber folgenden Mitteln:

1. Arg. nitr. $1: 4000$ und $1: 1000$.

2. Aethylendiaminsilberphosphat $1: 4000$.

3. $1 / 4$ Procent Kresol.

4. $1 / 4$ Procent Aethylendiamincresol.

Endlich wurden noch zwei Desinfectionsversuche mit Staphyloc. pyog. aureus-Aufsehwemmungen, denen Silberphosphat $1: 2000$ bezw. $1 / 2$ procent. Aethylendiaminkresollösung zugesetzt wurde, auf ihre Richtigkeit controlirt. ${ }^{1}$

Nur in einem einzigen Falle ergab sich ein etwas genaueres Resultat; bei der Desinfection einer Aufschwemmung von Prodigiosusbacillen mit $1 /{ }_{4}$ Procent Aethylendiaminkresol war nämlich in einem Agargläschen noch

1 Ich bemerke, dass die betreffenden Versuche in der mannigfachsten Weise modificirt wurden, dass ich $_{1}$ sowohl auf Agar als auf Bouillon übertrug, und dass ich gewöhnlich je ein Gläsches mit drei Oesen und 5 . bezw. 15 Tropfen überimpfte. je nachdem aus der zweiten oder dritten Aufschwemmung übertragen wurde. 
nach 20 Minuten Wachsthum beobachtet worden, während die direct überimpften Bacillen nach 10 Minuten Expositionsdauer zum letzten Male gewachsen waren. In allen anderen Fällen aber erwiesen sich die Zahlenwerthe als richtig, da auch nach Vermeidung der Fehlerquelle die Resultate die gleichen waren. Ich halte mich demnach für berechtigt anzunehmen, dass für die in der Arbeit mitgetheilten Desinfectionsexperimente der oft genannte Versuchsfehler die Richtigkeit der Ergebnisse nicht merklich beeinträchtigte und demgemäss unberücksichtigt bleiben durfte.

Zum Schluss gestatte ich mir, meinem hoebverehrten Chef, Hrn. Prof. Neisser für die vielfache Anregung und Unterstützung, welche er mir bei dieser Arbeit zu Theil werden liess, meinen herzlichsten Dank auszusprechen. 
ÜBER D. DESTNFECTIONSWERTH D. AETHYLENDIAMTNSH,BERPHOSPHATS. 247

\section{Litteratur-Verzeichniss.}

1. Behring, Der antiseptische Werth der Silberlösungen und die Behandlung von Milzbrand mit Silberlösungen. Deutsche med. Wochenschrift. 1887. Nr. 37 u. 38.

2. Derselbe, Ueber Desinfection, Desinfectionsmittel u. Desinfectionsmethoden. Diese Zeitschrift. Bd. IX.

3. R. Koch, Ueber Desinfection. Mittheilungen aus dem Kaiserl. Gesundheitsamt. 1881. Bd. I.

4. J. Geppert, Ueber desinficirende Mittel und Methoden. Berliner klinische Wochenschrift. 1890. Nr. 11.

5. Spirig, Desinfectionswerth der Sozojodolpräparate nebst Bemerkungen über die Technik der Prüfung der Antiseptica. Diese Zeitschrift. Bd. XIII.

6. Buttersack, Beiträge zur Desinfectionslehre und zur Kenntniss der Kresole. Arbeiten aus dem Kaiserl. Gesundheitsamt. 1893.

7. M. Gruber, Ueber die Methoden der Prüfung von Desinfectionsmitteln. (Vortrag auf dem VII. internationalen Kongress für Hygiene und Demographie zu London.) Centralblatt für Bakteriologie. 1892. Nr. 11.

8. v. Esmarch, Die Milzbrandsporen als Testobject bei Prüfung von Desinficientien. Diese Zeitschrift. Bd. V.

9. O. Boer, Die Leistungsfähigkeit mehrerer chemischer Desinfectionsmittel bei einigen für den Menschen pathogenen Bakterien. Ebenda. Bd. IX.

10. Geppert, Zur Lehre von den Antisepticis. Berliner klin. Wookenschrift. 1889. Nr. 36 น. 37.

11. R. Stern, Ueber die Wirkung des menschlichen Blutes und anderer Körperflüssigkeiten auf pathogene Mikroorganismen. Zeitschrift für klinische Medicin. Bd. XVIII. Hft. 1 u. 2.

12. Bumm, Der Mikroorganismus der gonorrhoischen Schleimhauterkrankungen „Gonococcus Neisser“. 


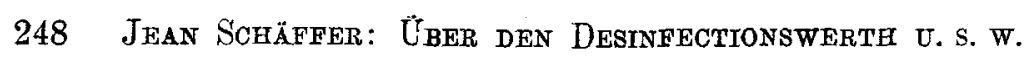

13. Kreis, Beiträge zur Kenntniss der Gonokokken. Wiener medicin. Wochenschrift. 1885. Nr. 30 .

14. Latteux, Bakteriologische Untersuchungen, die antiseptischen Eigensehaften des Ichthyols betreffend. Monatshefte für praltische Dermatologie. 1892. Bd. XIV.

15. Wertheim, Die ascendirende Gonorrhoe beim Weibe. Bakteriologische und klinische Studien zur Biologie des Gonococcus Neisser. Archiv f. Gynäkologie. 1892. Bd. XLII.

16. Steinschneider, Ueber die Cultur der Gonokokken. Berliner klinische Wochenschrift. 1893. Nr. 29.

17. F. Hüppe, Ueber Kresole als Desinfectionsmittel. Ebenda. 1891. Nr. 45. 